\title{
The Heart of the Matter: The Coaching Model in America's Choice Schools
}

Susan M. Poglinco

Amy J. Bach

Kate Hovde

University of Pennsylvania, hovdek@sp2.upenn.edu

Sheila Rosenblum

Marisa Saunders

See next page for additional authors

Follow this and additional works at: https://repository.upenn.edu/cpre_researchreports

Part of the Curriculum and Instruction Commons, Educational Assessment, Evaluation, and Research Commons, Educational Leadership Commons, and the Educational Methods Commons

\section{Recommended Citation}

Poglinco, Susan M.; Bach, Amy J.; Hovde, Kate; Rosenblum, Sheila; Saunders, Marisa; and Supovitz, Jonathan A.. (2003). The Heart of the Matter: The Coaching Model in America's Choice Schools. CPRE Research Reports.

Retrieved from https://repository.upenn.edu/cpre_researchreports/35

View on the CPRE website.

This paper is posted at ScholarlyCommons. https://repository.upenn.edu/cpre_researchreports/35

For more information, please contact repository@pobox.upenn.edu. 


\title{
The Heart of the Matter: The Coaching Model in America's Choice Schools
}

\begin{abstract}
The Consortium for Policy Research in Education (CPRE) at the University of Pennsylvania was contracted by the National Center on Education and the Economy (NCEE) in 1998 to conduct the external evaluation of the America's Choice school design. CPRE designed and conducted a series of targeted studies on the implementation and impacts of the America's Choice design. This report coincides with the publication of three separate studies by CPRE on the impact of America's Choice in a number of districts across the country using a variety of quantitative and analytic approaches. Those impact analyses and a stand-alone piece on classroom observations conducted in Cohort 4 schools can be viewed as separate pieces or as complements to the information presented in this report. Another recent CPRE publication from fall 2001 is a widely distributed report entitled, Instructional Leadership in a Standards-based Reform, a companion piece to both the impact reports and this report.

Disciplines

Curriculum and Instruction | Educational Assessment, Evaluation, and Research | Educational Leadership |
\end{abstract} Educational Methods

\section{Comments}

View on the CPRE website.

\section{Author(s)}

Susan M. Poglinco, Amy J. Bach, Kate Hovde, Sheila Rosenblum, Marisa Saunders, and Jonathan A. Supovitz 


\title{
The Heart of the Matter: The Coaching Model in America's Choice Schools
}

\author{
Susan M. Poglinco \\ Amy J. Bach \\ Kate Hovde \\ Sheila Rosenblum \\ Marisa Saunders \\ Jonathan A. Supovitz
}

May 2003
Consortium for Policy Research in Education University of Pennsylvania Graduate School of Education





\section{Contents}

List of Figures and Tables

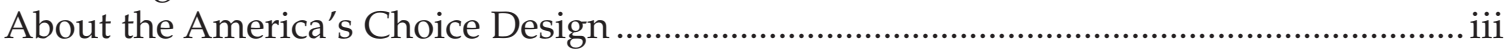

About CPRE's Evaluation of America's Choice ....................................................................... iv

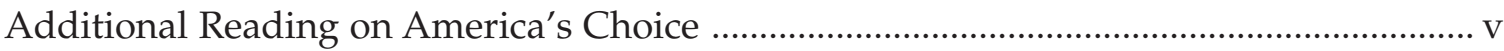

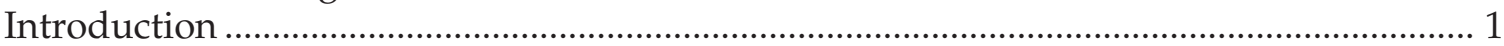

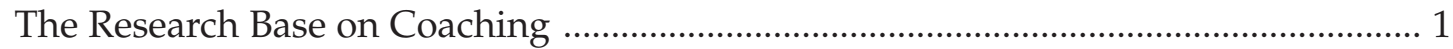

Structure and Focus of the Report .................................................................................. 2

The America's Choice Coaching Model and Research Design ............................................ 3

The America's Choice Coaching Model ....................................................................... 3

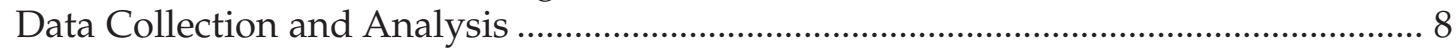

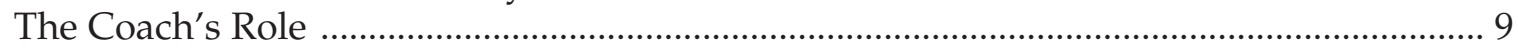

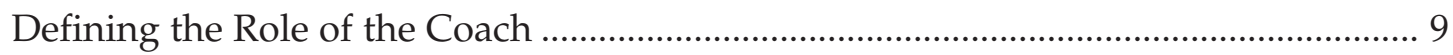

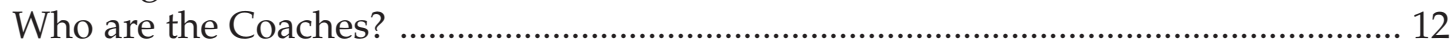

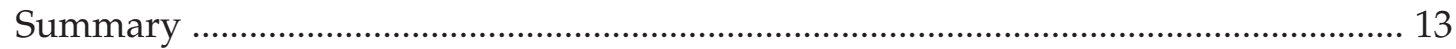

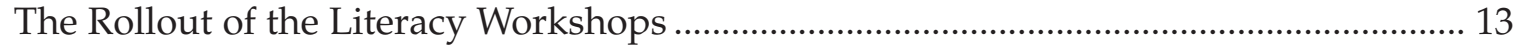

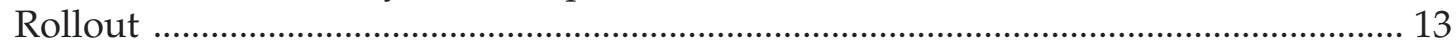

Fidelity of Rollout to Literacy Workshop Structures ...................................................... 15

Factors that Influenced the Rollout of the Literacy Workshops .................................... 17

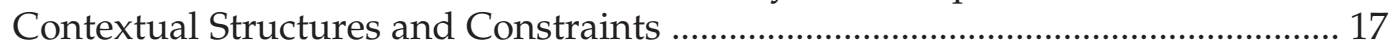

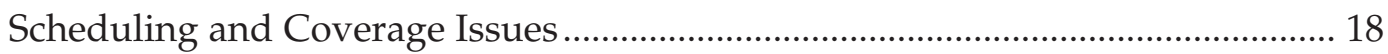

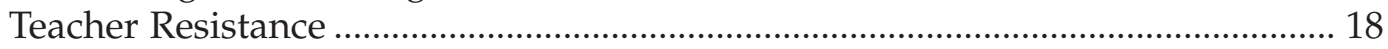

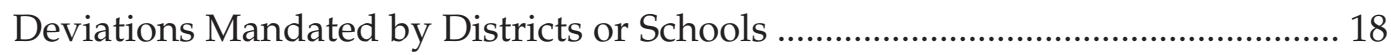

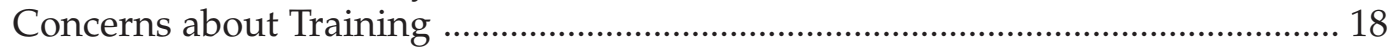

Principals' Knowledge about Rolling Out America's Choice ................................ 19

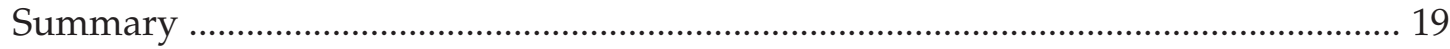

Technical Coaching: In-class and Individual Coaching Modalities ................................... 20

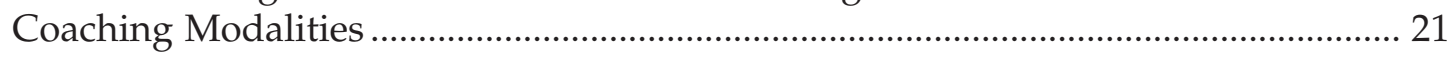

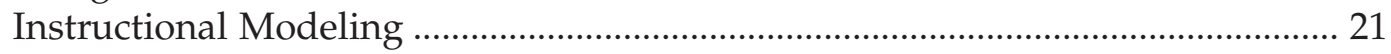

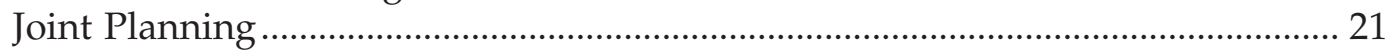

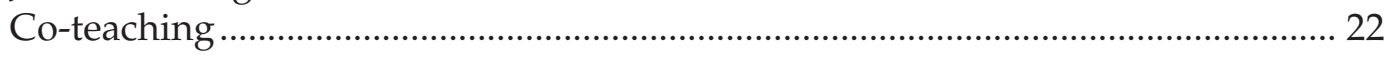

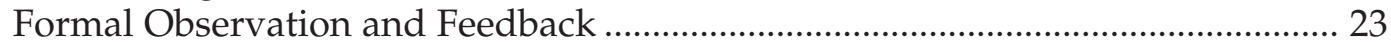

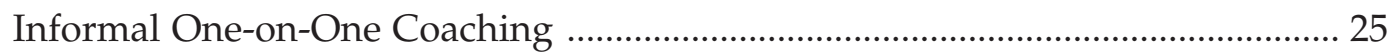

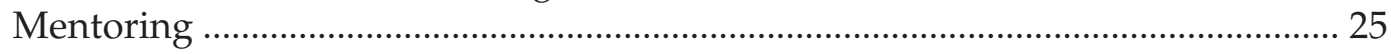

Reactions to In-class Coaching and Individual Support .............................................. 26

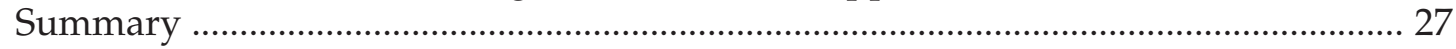

Group-focused Professional Development Activities at America's Choice Schools ........ 27

Group-focused Professional Development ................................................................... 28

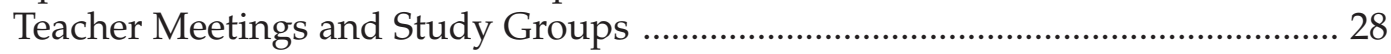

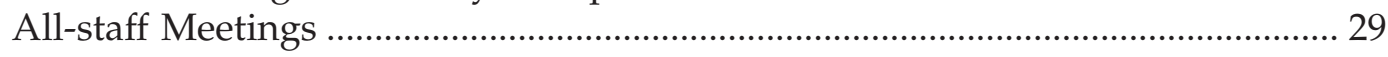

Identified Problems with Group-focused Professional Development Activities ....... 29

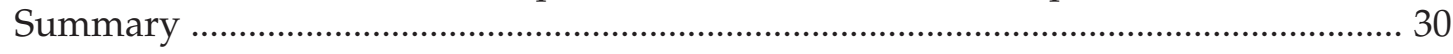

The Influence of Coaching on Standards-based Instruction ............................................... 31

The Content of Coaching: Where do the New Standards Performance Standards Fit

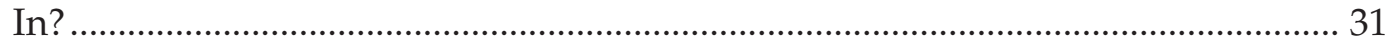

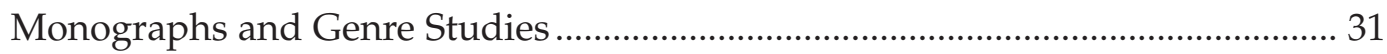

New Standards Performance Standards ............................................................. 32

Fidelity to Literacy Workshop Structures as Vehicles to Deliver Standards-based

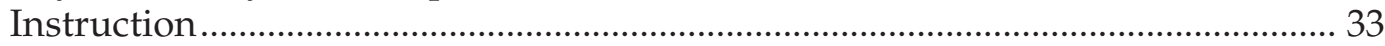

Critical Connections Between Group-focused Professional Development Activities

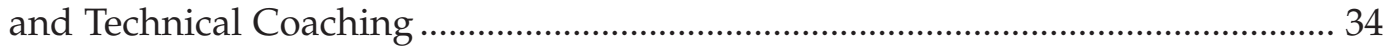


Comparing and Connecting Approaches to Professional Development .............. 34

Creating Professional Learning Communities ........................................................ 35

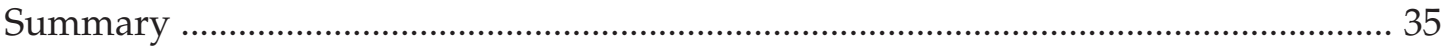

Summary of Factors that Influenced Coaches' Implementation of the America's Choice

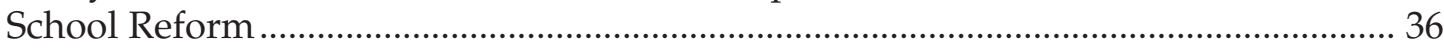

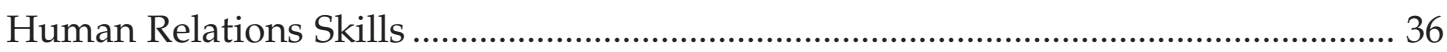

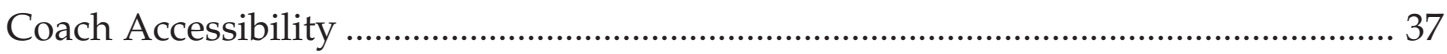

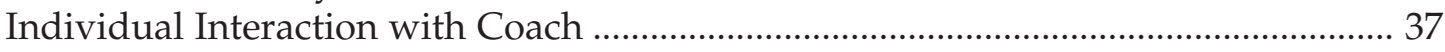

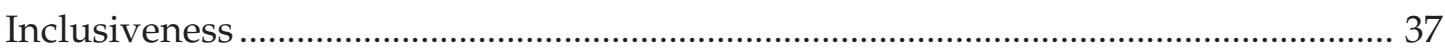

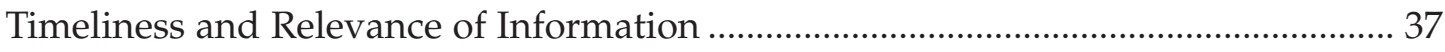

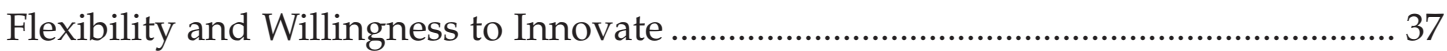

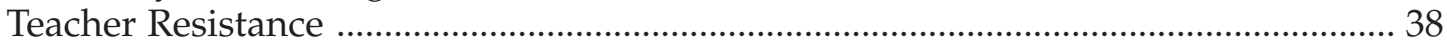

Understanding of Literacy Workshop Structures ......................................................... 38

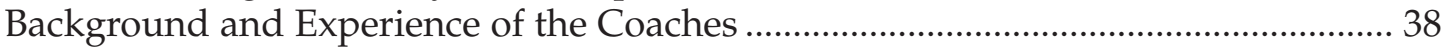

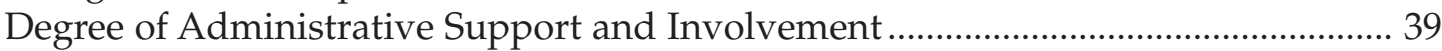

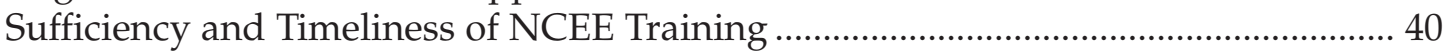

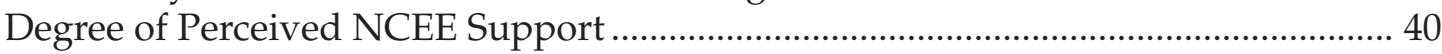

Perception of the Coaches' Role: Issues and Uncertainties .......................................... 41

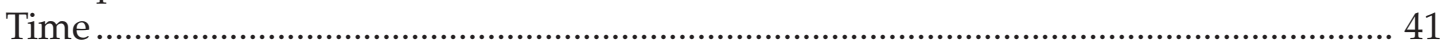

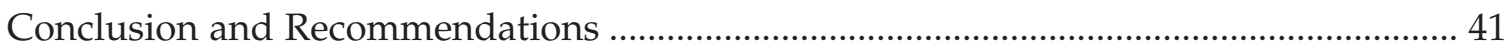

Influencing the Quality of Those Who Would be Coaches .............................................. 44

Better Preparing Coaches to do the Work of Standards-based Reform ....................... 44

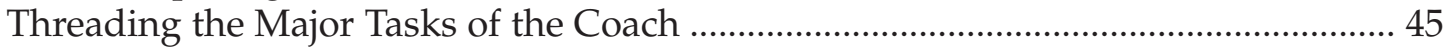

Better Support for the Work of Coaches ......................................................................... 46

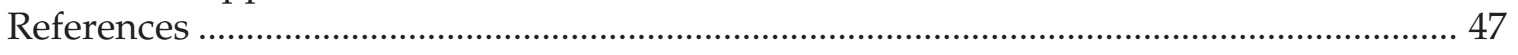

\section{List of Figures and Tables}

Figure 1. Coach's Role in America's Choice Professional Development ............................ 8

Table 1. Rollout of Literacy Workshops Across the Three School Levels .......................... 14 


\section{About the America's Choice Design}

The core of the America's Choice design contains a set of principles about the purpose of schooling and how schools should operate, and it provides a set of tools for building a program based on those principles. These essential principles and tools include:

- High expectations for all students, with communication of those expectations through explicit performance standards that are aligned to assessments and include examples of student work which meet the standards.

- The implementation of standardsbased literacy and math blocks, which happen every day for every child, and dramatically change teaching and learning in every classroom. The design's initial focus on literacy features the five key elements of reading instruction (phonemic awareness, phonics, vocabulary, fluency, and comprehension) using such strategies as oral language, shared books, and guided and independent reading. Writing instruction includes both daily and independent writing. The rituals and routines associated with these blocks are designed to prepare students to deal with demanding content and become independent learners.

- Ongoing assessment of students in order to inform daily instruction.

- School-embedded, ongoing, teacher professional development led by a full-time literacy coach designed to strengthen teachers' knowledge of the America's Choice approach to teaching and learning. This includes learning how to conduct a close analysis of their students' work in relation to standards, and using this knowledge to develop lessons calibrated to the needs of different students.

- Standards-based curriculum and instructional strategies that help students develop key skills, convey core concepts, and apply what they know.

- A school leadership team, led by the principal and subject-matter coaches, that coordinates implementation through a variety of means. These include setting performance targets and analyzing student work on a variety of measures, training teachers, adjusting school schedules, and implementing safety-net programs to provide time for students to receive additional instruction.

- "Safety nets," including tutoring and course recovery programs, that are structured into the school day and year, and that provide students with extensive support and multiple opportunities to achieve the standards. 


\section{About CPRE's Evaluation of America's Choice}

The Consortium for Policy Research in Education (CPRE) at the University of Pennsylvania was contracted by the National Center on Education and the Economy (NCEE) in 1998 to conduct the external evaluation of the America's Choice school design. Each year, CPRE designs and conducts a series of targeted studies on the implementation and impacts of the America's Choice design. This report is one of this year's evaluations, and coincides with the publication of three separate studies by CPRE on the impact of America's Choice in a number of districts across the country using a variety of quantitative and analytic approaches. Those impact analyses and a stand-alone piece on classroom observations conducted in Cohort 4 schools can be viewed as separate pieces or as complements to the information presented in this report. Another recent CPRE publication from fall 2001 is a widely distributed report entitled, Instructional Leadership in a Standards-based Reform, a companion piece to both the impact reports and this report.

The purpose of CPRE's evaluation is to provide formative feedback to NCEE and America's Choice schools about emerging trends in the implementation of the design, and to seek evidence of the impacts of the design using accepted high standards of evaluation design and analysis methodologies.

CPRE's evaluation of America's Choice is guided by three overarching questions. First, is America's Choice being carried out in the manner envisioned - that is, how are teachers and school administrators understanding and implementing the many facets of the reform design? Second, as a result of their implementation of America's Choice, are the instructional practices of teachers changing in ways that would improve student learning? Third, to what degree can improvements in student achievement be attributed to the design? Within this framework, annual evaluation studies target specific aspects of the America's Choice design for more in-depth investigation. To address these questions, the CPRE evaluation team gathers a broad array of qualitative and quantitative data to develop a rich and valid picture of the implementation process over time and to capture the impacts of the design on students and teachers. Our data sources include:

- Surveys of teachers and administrators in America's Choice schools nationwide.

- Site visits to schools across the country to observe classroom instruction, examine implementation artifacts, and interview teachers, students, and school administrators.

- Telephone interviews with NCEE staff, school faculty members, and school and district administrators.

- Document reviews.

- Observations of national, regional, and school-level professional development.

- Collection of student performance measures, including state and local tests, the New Standards Reference Examination, and more authentic samples of student work products.

After data collection, CPRE research team members analyze the data using appropriate qualitative and quantitative research techniques in order to identify patterns of intended and unintended consequences and to detect effects of the design on students, teachers, and schools. The results are presented in a series of thematic evaluation reports that are released each year. 


\section{Additional Reading o America's Choice}

The following evaluation reports are currently available from CPRE. Print copies are available at no cost by emailing cpre@gse.upenn.edu, or by calling (215) 573-0700. Copies can also be downloaded at www.cpre.org.

- The Relationship Between Teacher Implementation of America's Choice and Student Learning in Plainfield, New Jersey (Jonathan Supovitz and Henry May, January 2003)

- Impact of America's Choice on Student Performance in Duval County, Florida (Jonathan Supovitz, Brooke Snyder Taylor, and Henry May, October 2002)

- Implementation of the America's Choice Literacy Workshops (Jonathan Supovitz, Susan Poglinco, and Amy Bach, April 2002)

- Instructional Leadership in a Standards-based Reform (Jonathan Supovitz and Susan Poglinco, December 2001)

- Moving Mountains: Successes and Challenges of the America's Choice Comprehensive School Reform Design (Jonathan Supovitz, Susan Poglinco, and Brooke Snyder, March 2001)

- America's Choice Comprehensive School Reform Design: First-year Implementation Evaluation Summary (Thomas Corcoran, Margaret Hoppe, Theresa Luhm, and Jonathan Supovitz, February 2000) 


\section{Introduction}

In this report, the Consortium for Policy Research in Education (CPRE) explores the role of coaching in first-year (Cohort 4) America's Choice schools in grades $\mathrm{K}-8$ as it relates to the implementation of readers and writers workshops, referred throughout this report as the literacy workshops. The reasons CPRE decided to concentrate on the coach/ teacher relationship within the America's Choice design are two-fold. First, given that a coaching model was chosen by the designers of America's Choice as the main strategy to introduce standardsbased instruction into the classroom, it followed logically that CPRE learn more about the challenges and benefits that such a model entails for America's Choice schools. For the purposes of this report, then, other important pieces of the America's Choice design are not discussed in depth. That is not to say that the instructional leadership of a principal or the school design team in an America's Choice school is not an essential element of the overall design; they are simply not covered in detail in this report in the interest of addressing the heart of the matter, the coaching model in America's Choice schools.

Second, as a mechanism for the professional development of teachers, coaching is increasingly relied upon by schools and districts across the nation to train teachers on a particular set of instructional techniques and practices. By focusing on coaching, we hope that some of our findings regarding coaching in America's Choice schools may be helpful to other schools and districts experimenting with coaching models.

\section{The Research Base on Coaching}

The rationale behind having a coach in America's Choice schools is informed by and rooted in research on creating an effective professional development environment, one characterized by providing ongoing support to teachers and creating a community of practice with permanent structures focused on instruction and curriculum. The concept of coaching fills a particular, and promising, niche in the range of strategies to improve the capacity of teachers to provide high-quality instruction to their students. Supovitz (2001) assembled a framework, based on emerging research, of what effective professional development might consist. These included showing teachers how to connect their work to specific standards for student performance, immersing participants in questioning and experimentation, providing intensive and sustained experiences, engaging teachers in concrete teaching tasks based on their experiences with students, focusing on subject-matter knowledge and deepening teachers' content skills, and connecting to other aspects of school change. The America's Choice school capacity-building strategy, with coaching at its center, fits snuggly into this framework.

Coaching is a form of inquiry-based learning characterized by collaboration between individual, or groups of, teachers and more accomplished peers. Coaching involves professional, ongoing classroom modeling, supportive critiques of practice, and specific observations. We distinguish coaching from mentoring, which is usually used in reference to induction programs for new teachers.

Joyce and Showers (1982) are commonly attributed as the first researchers to seriously explore the promise of coaching. Calling their model "peer coaching," Joyce and Showers envisioned pairs of teachers coaching each other in a reciprocal way. They argue that coaching provides companionship and technical feedback, prompts the analysis of applications of knowledge to instruction, encourages the modification of instruction to meet students' needs, and facilitates the practice of new methods. 
There does not seem to be a standard model of coaching, and its application in particular reforms and contexts vary. The literature describes a variety of forms of coaching. Technical coaching is typically used to transfer new teaching practices into teachers' regular repertoires. Collegial coaching is used to increase teachers' professional dialogue and help them reflect on their work. Peer coaching is commonly defined as two or more professional colleagues working together to improve their professional knowledge and skills. Mentoring relationships between experienced and novice teachers are also often described as coaching.

Despite its promise, the evidence around the effectiveness of coaching as a central strategy for increasing the instructional quality of teaching and improving student learning is in its incipient stages. Most studies reinforce the notion that coaching is a promising strategy for instructional improvement. Joyce and Showers (1996) found that teachers involved in a coaching relationship practiced new skills and strategies more frequently and applied them more appropriately than did teachers who worked alone. Gamston, Linder, and Whitaker (1993) conducted a small study of a coach working with two teachers, and found that the experience fostered teachers' collegiality and deepened teachers' reflectivity. Kohler and Crilley (1997) studied a small sample of primary-grade teachers and found that teachers were more effective in their use of questioning strategies and facilitating students' interaction with their peers. Edwards (1995) studied 153 teachers and found that they had a deeper understanding of their classroom practices.

The evidence of the influence of coaching on teaching practices is by no means unanimous. Other studies have found no effects associated with coaching. Gutierrez, Crosland, and Berlin (2001) analyzed videos, surveys, and interviews of 12 teachers and 8 coaches and found that most coaching experiences did not help teachers to change their classroom activities and lessons in substantive ways. Veenman, Denessen, Gerrits, and Kenter (2001) examined the effects of a coaching program to train teachers in a Dutch primary school. They found that while the prospective teachers had significantly higher perceptions of their skills, experienced teachers did not rate them as more effective than teachers who did not participate in the program. It should also be noted that few, if any, studies provide evidence that coaching strategies, in whatever form, lead to greater student learning. In our review of the literature, we could find no research that provided evidence of the relationship between coaching and student learning.

\section{Structure and Focus of the Report}

As mentioned above, this report focuses on the coaching model in America's Choice as it relates to the implementation of the literacy workshops. Although the America's Choice design also employs a coaching model in the implementation of math standards, the literacy workshops are the main focus of rollout during the first year of America's Choice and seemed a logical focus for this study. We next describe the America's Choice coaching model for the literacy workshops in detail, and present our research design and data collection strategies. The remainder of the report follows from our understanding and investigation of different aspects of the coaching model: the role of the coach, the rollout of the literacy workshops in Cohort 4 America's Choice schools, the various ways in which coaches work in class and individually with teachers, the coach's role in facilitating group professional development, coaching in America's Choice schools in relation to the overall objective of fostering standards-based instruction, a summary of factors influencing coach effectiveness, 
and a conclusion raising some larger issues emerging from the research, as well as recommendations for the America's Choice design team. We also provide a summary of findings at the end of each section.

Given that CPRE's role is to provide formative evaluation information to the National Center on Education and the Economy (NCEE), an overarching question throughout the report asks, "Is the model being implemented as designed? If not, why not, and what can be learned from any departures from the model?" We were also interested in shedding additional light on a number of areas where the design is not specific, and interpretation of roles and responsibilities is left largely open to individual coaches and schools. We hope this report may provide a window into what coaching in America's Choice schools actually looks like, as well as the challenges that coaches, principals, and teachers face in trying to implement the model. From this picture, we then draw conclusions regarding a range of factors which seem to influence the effectiveness of coaches. Finally, we raise a number of issues that are intrinsic to the model itself.

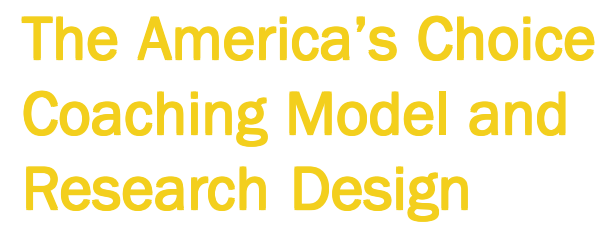

CPRE researchers began this study by reviewing all available written materials produced by NCEE about the literacy workshops, implementation strategies, and the role, training, and responsibilities of the coach. We supplemented this information with interviews of key NCEE literacy workshop designers and trainers, and our own previous knowledge of the design. We also attended a coach training session. From this body of information, we developed a model, or theory of action, of what coaches were supposed to be doing and how coaching was sup- posed to work in America's Choice schools. With this model in mind, we set out to gauge the extent to which actual implementation in the schools mirrored the theory.

\section{The America's Choice Coaching Model}

As indicated in the introduction, in the America's Choice design, coaches are the primary means for conducting teacher professional development and introducing the New Reference Performance Standards and literacy workshop structures into the classroom (see sidebar on page 4). In theory, every America's Choice school is required to appoint at least one full-time literacy coach (one for middle schools, and two at the elementary level). NCEE is responsible for providing both coach and principal training, which is conducted separately but is meant to be mutually reinforcing. Coach training is organized into several multiple-day training sessions spread throughout the year, although the timing of the training is such that most coaches begin their work with teachers after only one such session. Coaches receive additional support and oversight from cluster leaders, who in most cases are NCEE staff working with groups of schools at the regional level. Unless a coach or principal requests additional help or needs additional help in the view of the cluster leader, support from cluster leaders usually takes the form of monthly meetings at one of the schools forming part of the cluster. Cluster leaders and schools are also expected to conduct a joint "quality review" of implementation twice a year.

Coaches bear primary responsibility for the rollout of the literacy workshops in their schools although principals are expected to support and advise coaches in making school-level decisions about how rollout should proceed. NCEE prescribes a rollout process for both 


\section{Structure of the America's Choice Literacy Workshops}

The literacy workshops — readers and writers workshops - are organized around a sequence of activities that encompass group and individual work periods of either reading or writing. The workshops feature elements on phonics, oral language, shared books, guided reading, independent reading, daily writing instruction, and independent writing. Ideally, elementary schools should have a two or two-and-a-half-hour literacy block, one hour for writers workshop, one hour for readers workshop, and a half-hour skills block. Middle schools have less time allotted for their workshops because of the school schedule. Within the time period allotted for readers or writers workshop, there are certain rituals and routines that thread together and anchor the sequence of activities that occur in the workshop time period. Both the readers and writers workshops follow the basic structure of a short mini-lesson followed by an independent work period where students are given the opportunity to practice the topic of the mini-lesson. Workshops conclude with a closure session that ties back to the mini-lesson.

More specifically, writers workshop opens with a short mini-lesson of about 7-10 minutes. There are three kinds of mini lessons: procedural, craft, and skills. Procedural mini-lessons specifically focus on the rituals and routines of the writers workshop. Craft mini-lessons are geared to teach the elements of good writing like technique, style, and genre. Students learn the strategies that authors use to produce effective writing. Skills mini-lessons address the conventions of English like spelling, capitalization, punctuation, and paragraphs. Skills mini-lessons often incorporate student writing by using examples of student written work where conventions need to be reviewed. An independent work period, lasting 35-45 minutes, should follow in which students are engaged in the writing process, including planning, drafting, revising, editing, and polishing/publishing. Students work either individually or in small groups. Response groups provide students an opportunity to elicit feedback on drafts from a partner or small group of peers. Writers workshop ends with a short (five-minute) closure session, frequently author's chair, in which individual students share selections of their work in progress.

Readers workshop is structured to begin with a whole-class meeting in which the class might do a shared reading and have a mini-lesson in a 15-20 minute time period. The mini-lesson can cover phonics-based skills, decoding word analysis, comprehension skills, or procedures. This mini-lesson is usually followed by a period of independent/guided reading and/or reading conference period in which a number of activities like partner reading or book talks occur for about 45 minutes. In independent reading, students focus on reading appropriately leveled texts for enjoyment and understanding. Partner reading allows students to work with slightly more difficult texts, practice reading aloud, and model "accountable talk" and "thinkaloud" strategies. Reading aloud provides an opportunity for the teacher or other proficient reader to introduce authors or topics and model reading for the whole class. Shared reading allows the teacher to work with smaller groups of readers on reading strategies. Readers workshop may end with a book talk in which students share reactions to books read independently or to a book read aloud to the group. 
writers and readers workshops. This process differs for each of the school levels: the lower-elementary level, grades $\mathrm{K}-2$; the upper-elementary level, grades 35; and the middle-school level, grades 68. ${ }^{1}$ According to the Cohort 4 design, schools are expected to roll out writers workshop in the fall, and continue with readers workshop by spring of the first year, at least in the model classrooms. According to the design, lower-elementary coaches are expected to begin with the second grade, then move to the first grade followed by kindergarten; upperelementary coaches are expected to begin in the fourth grade and then move to the third grade followed by the fifth grade; the middle-school coaches are expected to begin in eighth grade and continue the rollout in seventh and then sixth grades.

Each school is to begin the rollout process by creating a model classroom where the coach "models" the implementation of the workshop components (both structure and content) for approximately six weeks. During this time, coaches are able to practice and hone their skills and knowledge of the America's Choice model, and at the same time form a partnership with the model-classroom teacher. ${ }^{2}$ It is expected that the modelclassroom teacher will gradually assume more responsibility for the workshop. The process differs somewhat with middle schools where teachers have several different classes in the course of a day. In middle schools, the coach is expected to model for one period, co-

1. We do not report on high schools in this report. Also, because school configurations and availability of coaches may vary across sites, the grades served at each level may also vary.

2. According to NCEE, the classroom chosen should be representative of other classrooms in the school in terms of student ability. In our sample, approximately one-quarter of the model classrooms (7 of the 27) were chosen by the principal or assistant principal. About one-fourth of the modelclassroom teachers believe they were selected by the coaches and about one-fourth were not sure how or why they were selected. teach for another period, and then observe the partnering teacher teach the lesson in a third period. Thus, the model classroom becomes the safe haven for coaches to hone their standards-based instructional skills.

After approximately six weeks in the model classroom, the demonstration phase begins. Coaches move to a demonstration classroom in the same grade and spend about three weeks conducting the workshop. Other teachers at the same grade level observe the demonstrations in order to learn how to lead the workshops themselves in their own classrooms that day or the next. Coaches are then expected to observe those teachers and provide feedback on whether teachers are implementing the workshops appropriately. The number of days for observation are not specifically prescribed and this varied significantly in Cohort 4 schools from 1 day to 20 days, largely because of the difficulty in getting coverage so teachers could be freed up to observe the demonstration classroom. At all three school levels, the design distinguishes between the model classroom and demonstration classroom. The model classroom serves as the coaches' training ground, while the demonstration classroom serves as the teachers' training ground. Although demonstrations are not expected to take place in the model classroom, NCEE suggests that the model classroom be available for viewing so teachers can see what an America's Choice classroom should look like. NCEE makes clear that the demonstrations should not extend beyond three weeks so there is adequate time for teachers to participate in a combination of demonstrations, teacher meetings, study groups, and school-wide professional development.

The America's Choice design explicitly requires that coaches take an active instructional role working with teachers, not only passing along information about the model and generally being support- 
ive, but actually modeling instructional techniques in the classroom. In the America's Choice design, the coach starts working with teachers from a position of greater expertise and exposure to the America's Choice instructional format and techniques. We refer to the kind of coaching envisioned in the America's Choice design as "technical" coaching because the coach has more technical knowledge of the America's Choice instructional design. While the design is very explicit about the coach's role in modeling of instructional techniques and even provides model lessons to help the coach get started, the design offers far less guidance about exactly how best to work with teachers, or what these relationships should ideally look like. Decisions on how to work with individual teachers are left to the judgment of the coach.

Coach-led or facilitated professional development activities in the America's Choice model are not limited to demonstrations and individual work with teachers. Also contemplated are schoolwide, group-focused professional development activities, which are organized into three distinct types: teacher meetings, study groups, and all-staff meetings. All-staff meetings may be led by the coach, but are more often led by the principal with coach input. These activities are defined and distinguished by NCEE as follows:

\section{Teacher Meetings}

- Teaching and learning teams

- Data-driven and standards-based

- Action-focus[ed] (e.g., using content to analyze student work, setting student performance targets)

Study Groups

- Focus on acquiring content knowledge (e.g., monographs, texts)

- Discussion/presentation guides
All-staff Meetings

- Key pieces of the design

- Action-focused

The purpose of teacher meetings is to deepen teacher understanding and confidence in using the standards and workshop structures in the classroom. This is accomplished through assignments (i.e., teachers are asked to try out a lesson, deadlines are provided) and through the analysis of student work in comparison to standards. The purpose of study groups is to acquire further content knowledge which is usually achieved through a review and study of research and through a review and study of curriculum materials, such as writers workshop lessons and monographs, genre studies, and other America's Choice materials. Finally, the purpose of all-staff meetings is to acquire new knowledge regarding the overall America's Choice design. As with technical coaching, a shared goal of these three types of meetings is to create professional learning communities within the school:

In order to create professional learning communities, all teachers must belong to teams that meet regularly with a coach for team meetings focused on student work and student learning. They need to participate in study groups that focus on the acquisition of new content knowledge. They need to be able to observe new approaches to teaching. Above all else, they need to receive support in the classroom as they themselves seek to improve their classroom practice. ${ }^{3}$

In addition to providing an overarching professional development structure, NCEE provides America's Choice schools with a timetable for holding group-focused activities and with discussion/presentation guides for leading these activities. According to the

3. NCEE, National Principals Academy, Summer 2001. 
America's Choice model, for example, teacher meeting \#1 should be held in November and should focus on "Conferencing." The stated purpose for teacher meeting \#1 is "to reflect on the writing conferences that have taken place in the classroom thus far, and to identify and practice effective strategies for conferring with students during the writers workshop" (NCEE, 2001, p. 7). Five suggested activities are provided, as well as materials that will be needed (in this example, the materials are the monograph on Writing Conferences). Similarly, study group \#1 should be held in AugustSeptember and should focus on "Rituals and Routines of the Writers Workshop." The stated purpose of study group \#1 is "to become familiar with the rituals and routines of the Writers Workshop," and "to be able to implement and teach the rituals and routines that allow the Writers Workshop to function smoothly in the classroom" (NCEE, 2001, p. 7). The monographs are also used in study groups (study group \#1 requires the use of Rituals, Routines, and Artifacts: Classroom Management for the Writers Workshop). A total of eight teacher meetings and five study groups are recommended in year one. Presentation and discussion guides are provided for all suggested teacher meetings and study groups.

The distinction between teacher meetings and study groups is sometimes subtle. In some instances, a suggested topic may be targeted for discussion in both study groups and teacher meetings as the following excerpt makes clear:

The America's Choice professional development is theoretically based and practically situated, and it is provided to school staff throughout the year. Teachers access professional development through regularly scheduled Study Groups that focus on the acquisition of new content knowledge (e.g., the America's Choice monographs on reading and writing) and through Teacher Meetings within grade levels or subject areas that center on applying new knowledge to classroom practice. In addition, all-staff meetings help build school-wide understanding of standards-based reform and planning for results. ${ }^{4}$

For example, study group \#2 and teacher meeting \#1 encompass the topic of "Conferencing." For both activities, the monographs are referenced. However, the guide for study group \#2 focuses on a discussion of the material and provides a "script" of sorts for the literacy coach (e.g., offer a general introduction, refer to a page in the monograph, etc.), while the guide for teacher meeting \#1 provides a number of activities that focus on the same topic (e.g., ask teachers to respond in writing to a prompt, ask teachers to break into groups and hold discussions, record responses on chart paper, etc.). Study groups are centered on a discussion of a given topic and focus on the dissemination of information that teachers are expected to bring back to the classroom. Teacher meetings, on the other hand, are action-focused and attempt to link information to and from the classroom through the use of student work. Teacher meetings create a two-way flow of information wherein student work from the classroom informs teachers' knowledge (through an analysis of student work) and knowledge flows from teacher meetings back to the classroom.

Figure 1 illustrates the CPRE research team's best visual representation of the America's Choice coaching model, part of the theory of action for delivering America's Choice professional development in schools. For the purposes of this report, the coach is placed at the nexus (A) between what we called the in-class technical coaching model (C), and group professional development (D), defined here as teacher meetings, study groups, and all-staff meetings. The technical coaching model is comprised of in-class and individual-level support provided by

4. NCEE, LAUSD Institute 1, Summer 2001. 


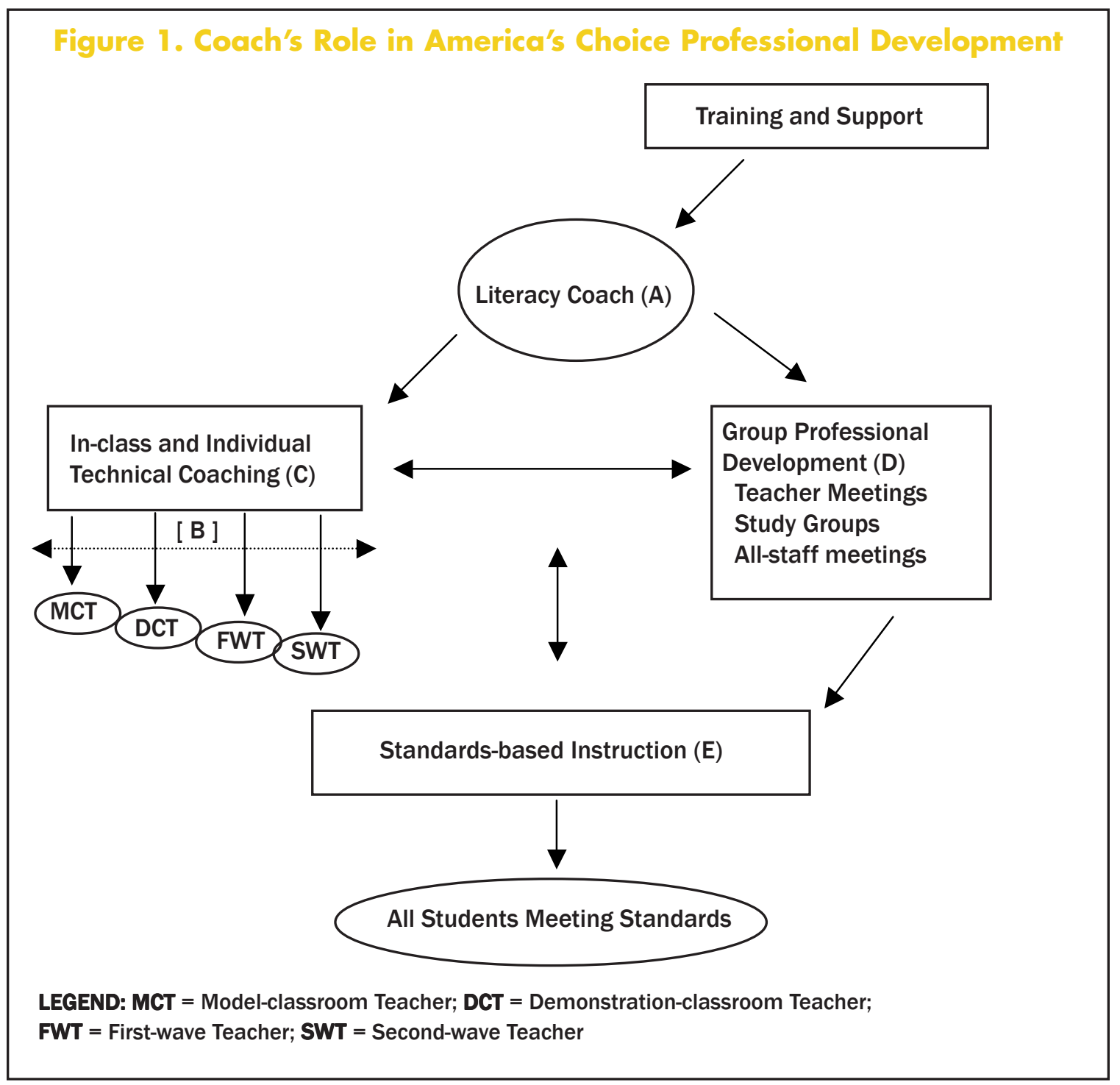

the coach to teachers. The arrows below the coach (B) represent the rollout strategy and lead to different waves of teachers who work with the coach to implement the literacy workshops: the modelclassroom teacher (MCT), the demonstration-classroom teacher (DCT), the firstwave teacher (FWT) (meaning a teacher who was part of the first wave of implementation of the workshops), and the second-wave teacher (SWT) (a teacher who was part of the second wave of implementation of the workshops). We also include dotted arrows between teachers because we posit that some peerto-peer coaching might evolve through grade-level meetings or other professional development activities related to America's Choice. The bottom portion of the figure represents the purpose of this system, which is to produce standardsbased instruction in classrooms (E) and lead all students to meet the standards. NCEE training and other support to coaches is represented by the rectangle at the top right, but as an area outside the coach's direct responsibilities and sphere of influence is not given a letter, and is discussed within this report as one of several factors influencing the coach's ability to implement the model as designed.

\section{Data Collection and Analysis}

To collect the evidence to produce this report, we visited America's Choice schools across the nation and collected 
data on teachers' and coaches' implementation and understanding of the

America's Choice literacy workshops, as well as their views regarding critical aspects of the design and training, and the coaching model itself. We observed both teachers and coaches in the classroom, and rated observations based on an implementation scale we developed (please also refer to Implementation of the America's Choice Literacy Workshops, a CPRE report on classroom observations of coaches and teachers in Cohort 4). We conducted post-observation interviews with teachers and coaches whose classes we observed, and interviewed the principal in each school.

We sought a sample to serve as a representative set of classrooms and schools from across Cohort 4 elementary and middle schools. At the time of the study, there were about 400 schools in all four cohorts of the America's Choice design. We decided to focus our resources on the most recent cohort of America's Choice schools because the design had undergone substantial modifications since its first year. The schools in Cohort 4 were implementing the design for the first time in 2001-2002.

Our sampling procedure followed several steps. First, we purposefully selected six locales in which America's Choice was being implemented (California, the District of Columbia, Georgia, Illinois, New Jersey, and New York). From within these locales, we sought regions in which America's Choice schools were not too dispersed so that we could cost effectively visit multiple schools during the same site visit. These regions included rural areas as well as urban districts. From within these regions we randomly sampled 27 schools to visit for a day-and-a-half each. Schools were designated lower-elementary schools, upper-elementary schools, and middle schools, and visited between March and May, 2002. A school's designation dic- tated which grade levels would be the focus of the observations and interviews conducted in that school with teachers and coaches. In the nine lower-elementary schools, CPRE targeted second-grade classrooms, interviewed second-grade teachers, and the lower-elementary coach. In the nine upper-elementary schools, the focus was on the fourth-grade classrooms, fourth-grade teachers, and the upper-elementary coach. In the nine middle schools, CPRE focused on eighthgrade classrooms, eighth-grade teachers, and the literacy coach.

Although our design called for three observations in each school, there were a few sites where we were not able to conduct all three observations and in some cases conducted interviews and observations outside of the target grades. Our final sample included 71 observations in 27 schools. From these interviews, we organized and analyzed the data into broad thematic areas and were able to see if our theory of action related to the different forms of professional development for teachers within the coaching model held up. We then refined and reviewed areas of the theory of action that did or did not hold up based on our data sources.

\section{The Coach's Role}

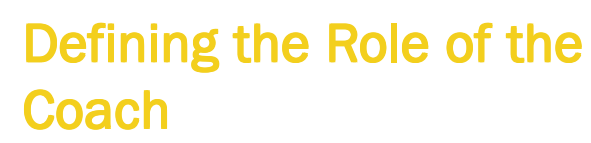

Despite the importance of the coach's role, there does not appear to be one "official" written job description for coaches that is shared by all America's Choice schools. Some coaches had never seen a written job description, or had seen an abbreviated one in the form of a job advertisement posted by the state, school district, or the school itself. Several coaches felt that the lack of a clear definition of their role from the outset made their job difficult, and contributed to 
misunderstandings with the school administration and/or teachers. These coaches also felt that America's Choice needs to work harder to ensure that coaches, principals, and cluster/team leaders have a mutual understanding and shared expectation of the role and responsibilities of the coach. Conflicting expectations were apparent regarding the amount of support and dedicated time coaches needed to get America's Choice workshops up and running in classrooms.

Most coaches came to understand their role through a combination of experience and training they received through America's Choice literacy institutes. Most coaches understood their jobs to include: setting up a model classroom, modeling America's Choice instructional techniques to teachers with students in a classroom setting, conveying information to teachers about America's Choice through teacher meetings, and generally serving as a resource to teachers implementing writers and readers workshops in their classrooms. As discussed in more detail later in this report, there was substantial variation among coaches as to the degree to which joint planning, teacher observation, and feedback were part of their role. Coaches also varied in what they felt to be the appropriate balance between being a help and being a "crutch" for teachers. Coaches differed in the initiative or confidence they displayed in adjusting the America's Choice model, rollout plan, and materials to their school setting. There was also considerable variation between the actual organization and content of group-focused professional development (teacher meetings, workshops and study groups) and that suggested by NCEE. To some degree this variation was dictated by local circumstances (such as time constraints), while in at least a few cases, coaches stated that they simply did not understand that they were supposed to be running regular teacher meetings on
America's Choice until well into the school year.

A number of explicit and implicit expectations about the role and skills of the coach emerged from interviews with NCEE staff, principals, coaches, and teachers. When principals were asked about their criteria for the selection of coaches (not all of the coaches were selected by principals), those mentioned most often were teaching ability, reputation in the school, and personality. In the words of one principal:

My selection of the coach was based on my observations in the classroom and an informal school leadership survey. Also it was based on conversations between me and other individuals at the school. I selected her because her expertise was recognized by the staff, she had "followers" already, and showed flexibility in working with me.

Because the coach is expected to model instructional techniques in the classroom, it makes sense that teaching ability would be an important skill. As a staff developer for adults and a pointperson for a major reform, the America's Choice model also implicitly expects the coach to have leadership, communication, and facilitation skills, which in interview responses were often lumped into a broader category of "personality" or "people skills."

When coaches were asked what skills they thought were needed to be an effective coach, they tended to emphasize the importance of teaching experience and thorough knowledge of subject matter, as well as a host of people-oriented skills, including tact, patience, good communication abilities, and flexibility. Interestingly, although principals and coaches both mentioned the importance of teaching ability and subject-matter knowledge, rarely did they get more specific. For example, only three coaches 
mentioned the importance of a thorough knowledge of standards despite the centrality of standards-based instruction to the coach's role. Similarly, no one mentioned the ability to run effective meetings, although two coaches mentioned administrative experience as extremely useful, but this specific skill may be covered under more general comments regarding good communication skills. As members of the school leadership team, coaches are also implicitly expected to work with the principal and/or other school administrators and exercise both strategic planning and program monitoring skills.

Among the coaches' multiple roles and responsibilities, we detected some inherent tradeoffs and tensions. As noted by several principals, it is not always wise or accurate to assume that an exemplary teacher of children can also qualify as an effective adult educator or staff developer. Some coaches seemed to spend a lot of time demonstrating the literacy workshops in the classroom in part because they obtained most of their job satisfaction from working with students rather than from working with resistant teachers in the workshops. Similarly, while there are advantages to selecting a coach who is a teacher already respected in the school, that teacher may be less likely to possess well-honed administrative and facilitation skills and a specific knowledge of standards-based reform than someone hired through a broader search process.

Interviews with teachers, principals, and coaches also indicated that there was confusion about how to manage the inherent tension between being a teacher and a colleague of teachers, and being a quasi-administrator or manager. This tension was particularly acute in California and Georgia. In California, coaches mostly rotated between being coaches and in-class teachers during the same school year; former coaches were not sure to what degree they were responsible for responding to teacher requests for coaching when they were in their in-class teaching capacity. In Georgia, at least one coach per school had been hired by the state rather than the school, and was in the awkward position of both being a school "outsider" and simultaneously reporting to the school administration and the state supervisory team.

Most coaches and principals saw the coach's role as different from that of an administrator, and several thought that taking on an administrative role with inherent evaluative responsibilities would diminish the coach's effectiveness. For example, one principal stated:

\section{I think that person [the coach] must remember that although they are the language arts literacy person, they must not take the persona of an administrator. I have seen in my experiences that when that persona is taken on, it is not effective.}

Several coaches also made it clear that their approach to coaching depended on their being seen as a colleague by other teachers. In the words of one coach:

\section{It is important to take the position as a coach and know what that is, and realize that you're not a director, directing people what to do. And if that relationship is established, where you both [the coach and the teacher] make decisions, that the coaching is just suggesting [but] it's the teacher's classroom, and the teacher can see where it fits in, and you can work together for the benefit of the students.}

Nonetheless, the coach's role in the America's Choice design does appear to be evaluative at least in an informal way. For example, coaches are responsible for observation and giving feedback to teachers regarding their classroom implementation of the workshop components. For good or ill, coaches made judgments about who was implementing the work- 
shops and who was not. Some coaches were reluctant to push their own authority unduly, and looked to the principal for support and "follow-through" with teachers with whom they were having trouble. Many principals also acknowledged that follow-through with resistant teachers was a form of support they provided to coaches. Yet coaches' reliance on administrative support could backfire if the administrative response was heavyhanded and if teachers felt that the coach had not communicated expectations clearly. In at least two schools, teacher resistance to the coach increased dramatically after teachers felt themselves to be unfairly rebuked by the principal for noncompliance to the America's Choice model.

\section{Who are the Coaches?}

Given the expectations of the coach's role and skills outlined above, how do the formal qualifications of coaches working in America's Choice schools compare? The coaches in the sample of schools CPRE visited were a diverse group and came from a variety of backgrounds. There were both "insiders" and "outsiders" in the schools, and varied along a number of dimensions like prior experience in administrative or quasi-administrative roles, prior experience in staff development or school-wide programs, and previous experience with standardsbased reform. While the background of coaches demonstrated effort by America's Choice and district personnel to recruit people with experience relevant to the job, the diversity also illustrated how difficult it is to find a single person whose profile matches the combined expectations of the role.

The most consistent qualification among the coaches interviewed was prior teaching experience. All of the coaches had classroom teaching experience, ranging from 4 years to 32 years. Most were seasoned teachers with 8 or more years of teaching experience. In addition, a substantial number of coaches (12 out of 29) had also held out-of-class program coordination, staff development, or instructional support positions prior to assuming the literacy coach role. Two coaches had held assistant principal and/ or administrative positions. Thus, almost half of the coaches came straight from the classroom, and half had some additional school-wide or out-of-classroom experience, which many found to be helpful as coaches. One coach commented, "I already had a relationship with them [the teachers]. I've done workshops here as part of my job, so it was a natural flow."

In contrast, at least one of the coaches who was having trouble said that the America's Choice coaching position had been her first experience teaching adults and that the role may not have been a good fit for her. Four coaches had either bilingual certification or spoke Spanish; one coach had prior experience working in adult education. Five coaches had specific knowledge of, or experience with, reading, literacy, and/or balanced literacy programs.

With regard to standards-based reform, while 19 of the 29 coaches reported that they had some familiarity with standards-based reform prior to implementing America's Choice, 8 of these classified their knowledge as "limited" or said they were only "somewhat" familiar with such reforms or approaches. Very few had any knowledge of the specifics of the America's Choice model prior to agreeing to serve as literacy coach. Given that America's Choice coaches are specifically expected to model and promote standards-based instructional practices in the schools, the fact that almost two-thirds had only very limited exposure to standards basedreform presented a major challenge for coach training and full implementation of the America's Choice literacy workshops. 
The vast majority of coaches (20 of the 29) were "insiders" - that is, they had previous experience in the school in which they were coaching; some were classroom teachers, while others had different roles in the school. In most cases, schools had insufficient budgets to hire a coach from the outside. Moreover, many principals felt teacher resistance to the America's Choice model could be minimized by selecting teachers respected by their peers to serve as coaches. Also, coaches stressed the importance of strong collegial relationships in helping to ease the difficulties and frustrations of trying out innovations in the classroom. While several coaches reported that having had a previous relationship with teachers was an asset, in some cases assuming the role of coach strained relationships as teachers perceived the coach to be more of an administrator or supervisor than a colleague.

Nine coaches were new to their schools, appointed by America's Choice staff at the state level. Most of these were in Georgia, where the current policy is to let the school select one of the coaches while the state appoints the other. While several of these coaches had particularly strong formal qualifications (prior staff development and administrative experience, for example), as mentioned earlier, their "outsider" status within the school was often an additional barrier to be overcome. Several principals were concerned about their lack of say in the selection of the coach and attributed problems to their exclusion from the hiring process. Others stated that they had been able to develop a cooperative relationship with the coach irrespective of the assignment process and that "when you are given a glove, you make it fit!"

\section{Summary}

There is no single, detailed job description for coaches, and our interviews picked up a good deal of uncertainty in the minds of principals, teachers, and coaches about the role and responsibilities of the coach. In particular, there was a perceived tension regarding whether the coach was more of a teacher/colleague or an administrator. This tension was particularly acute in California, where coaches rotated between coaching and a normal teaching position. The position and implicit expectations of the coaching role also demand a very wide range of skills - probably more than can be easily found in a single person. There are also implicit tradeoffs in the selection of coaches: although the choice of a respected teacher in a school may diminish teacher resistance, it is also less likely that such a person has a strong background in standards and/or staff development. Although all coaches had teaching experience, few had extensive experience with standards-based reform and only one or two had previous familiarity with America's Choice.

\section{The Rollout of the Literacy Workshops}

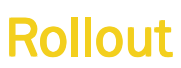

Based on site visits to schools and interviews with coaches, principals, and teachers, CPRE researchers learned that the actual rollout of the America's Choice literacy workshops did not necessarily follow the process envisioned by NCEE in the design and incorporated in the coaching model described earlier. There was substantial variation in the process ranging from almost complete fidelity to the prescribed rollout sequence in 4 of the 27 schools, to broader deviation from the sequence in many schools. There was considerable deviation from the model with regard to coach demonstration of the literacy workshops to teachers. While all coaches started in a model classroom with the model-classroom teacher, ${ }^{5}$ many

5. One school did not have a model classroom because there was no literacy coach at that site. 


\section{Table 1. Rollout of Liferacy Workshops Across the Three School Levels}

\begin{tabular}{|c|c|c|c|}
\hline Dimensions & $\begin{array}{l}\text { Lower Elementary Schools } \\
\qquad(\mathrm{N}=9)\end{array}$ & $\begin{array}{l}\text { Upper Elementary Schools } \\
\qquad(\mathrm{N}=9)\end{array}$ & $\begin{array}{l}\text { Middle Schools } \\
\qquad(\mathrm{N}=9)\end{array}$ \\
\hline $\begin{array}{l}\text { Complete rollout of } \\
\text { writers workshop }\end{array}$ & 4 schools & 7 schools & 1 school \\
\hline $\begin{array}{l}\text { Number of weeks coach } \\
\text { was in model classroom }\end{array}$ & 6-8 weeks (8 schools) & $\begin{array}{l}4 \text { weeks ( } 3 \text { schools) } \\
6 \text { weeks ( } 3 \text { schools) } \\
8 \text { weeks ( } 3 \text { schools) }\end{array}$ & $\begin{array}{l}4 \text { weeks ( } 4 \text { schools) } \\
4-6 \text { weeks ( } 2 \text { schools) } \\
8 \text { weeks ( } 3 \text { schools) }\end{array}$ \\
\hline $\begin{array}{l}\text { Model classroom also } \\
\text { served as demonstration } \\
\text { classroom }\end{array}$ & 2 schools & 1 school & 3 schools \\
\hline $\begin{array}{l}\text { Demonstration } \\
\text { classroom in each grade } \\
\text { level }\end{array}$ & 3 schools & 5 schools & 2 schools \\
\hline $\begin{array}{l}\text { Coach began rollout of } \\
\text { readers workshop }\end{array}$ & 4 schools & 3 schools & 1 school \\
\hline
\end{tabular}

Note: These data reflect what was learned at the time of the CPRE visits, which took place between mid-March and early May of 2002.

coaches demonstrated for individual teachers in their classrooms even if they also had an official demonstration classroom. According to our data, 6 of the 27 schools did not have an official demonstration classroom, and in two designated demonstration classrooms, coaches reported that no one ever came to observe writers workshop. On the other hand, one middle school required teachers to observe 10 times, and one elementary school required teachers to observe every day for over three weeks. In one district, teachers were expected to observe for four weeks.

There were somewhat different patterns of rollout for each of the three levels (lower elementary, upper elementary, and middle schools) on a variety of dimensions. Some of these differences were both between levels and within levels. The different patterns of rollout for each level are presented in Table 1.

Elementary schools, in both the lower and upper grades, were more successful than middle schools in rolling out writers workshops. The upper-elementary level was particularly successful, completing rollout to all but two of the nine schools. Upper elementary also had the most schools where there was a demonstration classroom at each grade level, which may explain their greater success at rollout. There were more opportunities for teachers to observe the writers workshop relatively early in the rollout process, as well as to have demonstrations in their own individual classrooms. As one upper-elementary coach described:

I began in fourth grade in a model classroom and spent six weeks. I then moved into demo class for four weeks. All third-and fifth-grade teachers were brought into the demo at least twice. As other teachers began to implement, I did at least one lesson in each classroom and more upon request.

In many schools at all three levels, coaches found they had to do most of the demonstrating for individual teachers in their classrooms, rather than in a demonstration classroom, and this took a significant amount of time. Elementary schools at both levels were also more successful 
in beginning the implementation of readers workshops. This took place in 7 of the 18 elementary schools, and in only 1 of the middle schools. In one school, the coach moved on to readers workshop without successfully implementing the writers workshop first because of resistance from teachers.

As shown in Table 1, literacy coaches in our sample spent from four-to-eight weeks in the model classroom, but not on a daily basis. Coaches also spent a substantial amount of time at their own training sessions, network meetings, and attending to other demands from the school and district. Across the three levels, there were six schools in which the model classroom also served as a demonstration classroom, which is a deviation from the prescribed rollout process.

The middle schools had the greatest challenge in implementing readers and writers workshops and only one of the nine schools in our sample managed to complete the rollout to all the intended classrooms. Furthermore, unlike both elementary school samples, only one middle school began to implement readers workshop during the school year by the time they were visited by CPRE researchers.

In four of the middle schools, there was not a designated demonstration classroom. In one of the schools, instead of having a demonstration class, the coach modeled the America's Choice model lessons for three eighth-grade teachers during an in-service workshop. In another middle school with a demonstration classroom, no teacher ever came to observe. Overall, in middle schools, the primary rollout strategy was for the literacy coach to demonstrate for each teacher individually. This time-consuming strategy may explain why rollout was lagging in most middle schools. A typical example was seen in one middle school where the coach spent almost eight weeks in the model classroom and then demonstrated for six weeks each for other eighth-grade teachers. She found that bringing teachers into a single demonstration classroom did not work because of scheduling, and because teachers were at different stages and working on different content.

\section{Fidelity of Rollout to Literacy Workshop Structures}

To examine the fidelity of rollout, we conducted 65 observations of teachers and literacy coaches in our site visits to the 27 Cohort 4 schools. To assess these lessons, CPRE researchers developed a holistic rubric to measure their fidelity to the America's Choice writers workshop structures. Applying the rubric, classroom observations were rated largely according to the presence of the three key structures that make up writers workshop: the minilesson, the independent work period, and the closing session as well as the artifacts present in each classroom and the teacher's description of the purposes and goals of the lesson. The holistic rating scale is as follows:

\section{Stage 1: Absent or minimal struc-} tures of readers or writers workshop. Lessons with a rating of 1 showed little or no resemblance to the literacy workshop structures. In these classrooms, teachers essentially avoided the workshop structure in favor of other instructional approaches.

\section{Stage 2: Partial implementation of} workshop structures. Lessons with a 2 rating had some evidence of implementation of the structure of the America's Choice workshop, but were missing some major component(s). The absence of workshop structures suggested that the teacher had only a superficial understanding of the purpose of the workshops. 
Stage 3: Solid adherence to workshop structures. Lessons that received a 3 rating were faithful to the America's Choice literacy workshop structures. These classrooms had evidence of all three parts of the literacy workshop (mini-lesson, independent work period, and closing session) and each part was executed in proper order. While these classes showed solid adherence to the workshop structures, they lacked evidence of details (i.e., conferencing, standards) that would indicate that the teacher had a deeper understanding of the purposes underlying the workshop structures.

Stage 4: Exemplary implementation of workshop. Lessons that received a rating of 4 were exemplary lessons that not only adhered to the workshop structures, but also contained evidence that the teacher had a deep understanding of the purposes behind the structures.

The results of our ratings indicate that in $2002,62 \%$ of teachers at the end of their first year of implementation of writers workshop were at least solidly (stage 3 or 4) implementing the writers workshop design. About a quarter of the teachers we observed were partially implementing the writers workshop design. Just over $10 \%$ of the observations showed little or no resemblance to the writers workshop design. Ratings were generally higher in the elementary school grades (1-5) than in the middle school grades (6-8).

We compared the ratings of the 45 Cohort 4 teachers and the 20 Cohort 4 literacy coaches that we observed. In general, we observed two teachers in the school of each coach, although circumstances sometimes dictated fewer. Based on these observations, Cohort 4 literacy coaches performed somewhat better than the teachers they were instructing and guiding. In only one literacy coach classroom observation did CPRE researchers have difficulty detecting evidence of the writers workshop structures, whereas in six, or $13 \%$, of the Cohort 4 teacher lessons there did not appear to be evidence of the workshop structures. About a quarter of both the teachers' and literacy coaches' classes evidenced only partial implementation of the writers workshop structure. Just over half (51\% of teachers' and $55 \%$ of coaches') of the classes exhibited solid adherence to the workshop structures. In just over $10 \%$ of the classes of both teachers and literacy coaches, there was evidence of exemplary implementation of the writers workshop structures. A Fisher's Exact ${ }^{6}$ test of differences in the distributions indicates that there is no statistical difference between the ratings of Cohort 4 teachers and literacy coaches $(p=.83)$. This indicates that, on average, coaches were implementing the workshops with no greater fidelity than were teachers after one year of America's Choice.

We were further interested in the relationship between teacher and coach ratings within the same schools. It seems to make sense that a teacher's ability to implement a new form of instruction would be no greater than their coach's ability to effectively model that form of instruction. To explore this line of inquiry, we developed a structural equation measurement model to examine the correlation between the ratings of teachers and coaches, taking into account the grouping of teachers within schools under a coach. We found that the correlation between coach ratings and teacher ratings was strongly statistically significant $(\mathrm{r}=.75, \mathrm{p}<.0001)$ after accounting for the relationship between teachers and their coach. This confirms that there is a strong link between the quality of coaches' implementation of writers workshop and teachers' abilities to implement the writers workshop structures. As goes the coach, so go the teachers.

6. A statistical test used to determine if there are non-random associations between two categorical variables. 
Factors that Influenced the Rollout of the Literacy Workshops

There was substantial modification to the rollout design across all three school levels, and several factors influenced the approach that coaches took in orchestrating the rollout. The following factors were not necessarily issues in every school, and each school was influenced by a different combination of factors. However, the factors discussed below were of concern in a sufficient number of schools to warrant discussion here. ${ }^{7}$

\section{Contextual Structures and} Constraints

The rollout process was often constrained by contextual conditions beyond the control of America's Choice coaches and other personnel. Interruptions because of year-round schooling and different scheduling tracks are a prime example. In California, all the schools visited by CPRE were "Concept 6," multitrack, year-round schools which have three tracks, with 167 days of instruction, rather than the usual 180 days that most calendars provide. Tracks are in session for 81 instructional days and then out for 43. At any one time, two tracks are in session and one track is on vacation. Given this scheduling, Concept 6 schools were faced with numerous complexities in implementing the America's Choice model.

Since at any one time, approximately one-third of a grade level was "off-track," providing demonstrations (and groupfocused professional development) and rolling out to an entire grade level depended upon what classes were "ontrack" and what classes were "off-track." For example, schools began rolling out to

7. The order in which the factors are discussed does not reflect their order of importance. the first or third grades prior to completing the second or fourth grades because classes in these grades were not "ontrack." Coaches found they needed to "return" to grade levels or were forced to move on to another grade level and complete the previous grade level at another time.

Time constraints forced coaches to hold off rolling out to new teachers until a new session began or an old session ended to avoid disrupting a demonstration for a two-month period of time. A few coaches said they made the decision not to begin new demonstrations because it was too close to a track change, and lost valuable time in rolling out the design. In one instance, teachers attended demonstrations prior to vacation, and began to implement writers workshop in their own classroom for a week before going on vacation for two months. A third problem experienced in Concept 6 schools was coach availability. A number of these schools did not have a full-time America's Choice literacy coach, and made the decision to use teachers during their off-track time to act as the coach. At these schools, demonstrations could not occur when the "coach" was back "ontrack," and this slowed down the rollout process.

Another example of a constraint was a middle school that was divided into three houses. Rather than try to roll out to all eighth graders in three houses, and moving down the grades, the coach made the decision to include the three grades in one house in order to take advantage of the meeting time available within the house for America's Choice discussions. This slowed down the process of rolling out to all eighth graders, followed by seventh and then sixth graders. At the time of the CPRE visit, only a third of the classes were implementing America's Choice writers workshops because up until then the coach had concentrated all her efforts in one house in that school. 


\section{Scheduling and Coverage Issues}

The prescribed process assumed that teachers would have the opportunity to observe the coach in a demonstration classroom and that, based on those observations, materials distributed, and what one learned in the group-focused professional development, teachers would move to implement the workshops in their classrooms. As it turned out, the rollout process proceeded in this manner in only a few schools. In many schools, coaches found that they had to demonstrate for individual teachers in their own classrooms because teachers were not able to observe the coaches' demonstrations, in large part due to scheduling and coverage problems. Teachers were not freed from their classrooms, either because there were insufficient substitutes available, not enough creative scheduling solutions to provide coverage, or lack of support or interest by teachers and administrators. This caused a substantial deviation from the rollout design.

\section{Teacher Resistance}

Teacher resistance was another factor that caused rollout variation. Not all coaches followed the prescribed rollout because they chose teachers who were most interested in implementing the literacy workshops and least resistant to the idea, even if they were not in the target grade. Coaches reported that by doing so, resistors would see success and enthusiasm and were more likely to buy in to the reform. The following example illustrates this point:

I chose teachers who expressed interest rather than do a rollout grade by grade. I worked with a seventh-grade teacher who had trouble with discipline, and another eighth-grade teacher. I later worked with two sixth-grade teachers. I am now working with a third sixth-grade teacher and two seventh-grade teachers, one of whom hasn't bought in and has a negative attitude.

\section{Deviations Mandated by Districts or Schools}

In at least three of the schools in our sample, the district or school leadership chose to concentrate on other priorities, such as upcoming standardized testing, and requested that coaches spend time in the grade levels that would be tested, working on "test prep" with the students. This diverted the coaches' time from the rollout design and slowed the rollout process considerably. A number of teachers said there were times when they could not concentrate on implementing literacy workshops because they needed to concentrate on teaching the skills likely to appear on the standardized tests. In these cases, teachers were not aware that they could work on the required test preparation skills in the context of the literacy workshops, and coaches were unclear how to convince them that this was possible.

\section{Concerns about Training}

Some coaches attributed their struggle with the rollout process to their own incomplete understanding of what they were expected to do. Coaches struggled with the idea of being just one chapter ahead of the teachers, and not always having the knowledge to respond to questions teachers posed. This was due to coaches' stepped preparation coupled with the pacing of their training from a national and regional standpoint. The coaches' perspective on concerns about training is summed up in the words of one coach:

If the training for everyone is very explicit and people have answers to all their questions and concerns, let's say over the summer, I think it is possible to roll out writers workshop from day one. Our problem was that we weren't really clear on the big picture of it. Yes, we got the training on this and that, but to be trained on it today to roll it out tomorrow 
when you don't understand it yourself is very difficult.

This concern was also expressed by a few principals. As one principal noted:

The literacy coaches are just one step ahead of the teachers. It diminishes their credibility and there is the danger of no follow-up. This needs to be emphasized because we are still in the process of rolling it out.

\section{Principals' Knowledge about Rolling Out America's Choice}

Principals' knowledge of the initiative was tied to most of the factors noted previously in this report as was their understanding of the model, its assumptions, and requirements. Teacher concerns about principals' knowledge of what it takes to roll out the literacy workshops were justified since principals helped to provide coverage for teachers to observe demonstrations, maintained a high profile with an emphasis on America's Choice implementation, and let resistors know that the literacy workshops were a priority.

Overall, principals were enthusiastic about the rollout process. They were positive about coaches demonstrating to teachers as a training strategy, but they had some general concerns about the model. As one principal commented:

Being able to watch someone demonstrate how the workshops should be taught is an invaluable way to learn how to implement the America's Choice workshops. Having a coach provides a support system for teachers that helps them implement the workshops. The weakness is that it is very time consuming. A lot of time is spent in training.

Some principals had concerns about the efficacy of the "train-the-trainer model" itself and some doubts about the dependence on coaches for rollout and implementation. The following comment by one principal reflects what was echoed by several others:

The coaches are very capable people, but because we are rolling out in the classrooms, it would be great to have the classroom teachers themselves get this training. That would be the ideal model for me with coaches there as a collective effort supporting what everyone has seen. A possible weakness in the model is the coach getting the information and not rolling it out as they were taught to do. But if everyone is there to see it together, teachers get to hear some things firsthand. In the current model, the coaches become the messenger. What we all should have is an expectation because of frontend discussions.

\section{Summary}

Major elements of the America's Choice design were successfully rolled out in all 27 schools that CPRE visited in the spring of 2002. All of the schools were successful in rolling out writers workshops in at least some of the grade levels and classes. However, less than half of the schools (12 of the 27) that CPRE visited completed the rollout of writers workshops to all target classrooms. The most complete rollout of writers workshop was accomplished in seven of the nine upper-elementary schools. Lowerelementary schools were somewhat less successful with the rollout of writers workshop in four of the nine schools. Middle schools had the biggest challenge, with only one school completing rollout of writers workshop.

NCEE expected readers workshops to be rolled out in the spring of the first year in Cohort 4, at least in the model classrooms. In fact, the rollout of readers workshops had begun in eight schools, or less than a third of the schools visited. At the time of the CPRE visits, implementa- 
tion of readers workshop was beginning in model classrooms in lower- and upperelementary schools and in only one middle school.

There was significant variation in how the rollout occurred in the different schools, although most schools followed the prescribed sequence of grade-level rollout. All but one school started with a model classroom (the one exception was a school without an assigned coach). The schools varied in how much time the coaches spent in the model classroom. The biggest variation was in the use of demonstration classrooms. The original intent was to have groups of teachers observe in demonstration classrooms and then be able to implement the workshops in their own classrooms. But, a number of schools did not have a demonstration classroom. Instead, coaches rolled out by providing multiple demonstrations in individual teachers' classrooms. Even in schools where a demonstration classroom existed and teachers did observe, many coaches spent time going to individual classrooms to demonstrate further. This was time consuming, and, for this reason, more than half the schools did not complete the rollout of the writers workshops, and even fewer began implementation of readers workshop. However, the more closely the schools followed the prescribed rollout process, the more likely they were to begin readers workshop in the first year.

Overall, the fidelity to the workshop structures was generally solid. Sixty-two percent of the lessons that we observed were rated as at least solid on our fourpoint implementation scale, while only $10 \%$ of the observed lessons showed little or no resemblance to the workshop design. Importantly, there was a high correlation between the fidelity of coach and teacher lessons within schools. This reinforces the notion that the success of teachers in modifying their instructional routines is highly dependent on their coaches' ability to model the new routines for them.

There are a number of factors that influenced modifications to the rollout process. These included contextual constraints (which were especially important in California), teacher resistance, principal knowledge of America's Choice, and the limitations of coaches' training. The America's Choice model expects schools can free teachers up to observe demonstrations, and participate in meetings to learn about and discuss elements of the workshops. While these conditions may help maximize rollout of the workshops and school-wide implementation in a compressed period of time, such conditions did not exist in all schools in our sample.

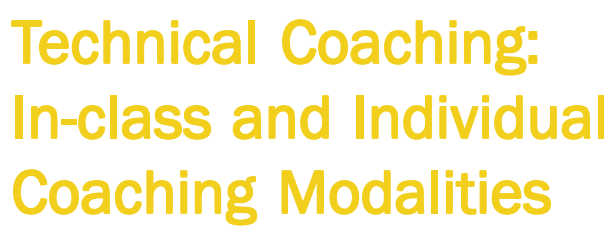

As noted earlier, the America's Choice coaching model is explicit with regard to the expectation that the coach will do inclass, instructional modeling for teachers. How coaches should approach and work with individual teachers, however, is left largely to the discretion of the coach. In addition to investigating to what extent coaches were doing such modeling, an objective of this study was to provide a concrete notion of what technical coaching on an individual and in-class level in America's Choice schools actually looked like. The following section discusses several coaching modalities gleaned from our interviews, along with coach and teacher perspectives on each. In addition to instructional modeling, these modalities include joint planning, co-teaching, formal observation and feedback, informal coaching support, and mentoring. 


\section{Coaching Modalities}

\section{Instructional Modeling}

Quite a few respondents equated America's Choice in-class coaching with instructional modeling - that is, the coach demonstrating America's Choice instructional techniques and materials for teachers in a classroom setting with students present. While the America's Choice coaching activities encompassed a broader range of activities, it was clear that instructional modeling was considered a central piece, and, in large part, what distinguished the America's Choice approach to professional development from other approaches. In the words of one teacher:

Over the years, in professional development activities, I have always said, "I'd like to see it with children." It is difficult to grasp something if you don't see it, if someone is just talking to you.

Almost all teachers in the schools CPRE visited were exposed to a coach doing instructional modeling, although in two schools, modeling was done exclusively in a meeting rather than a classroom setting. ${ }^{8}$ The amount of modeling to which teachers were exposed varied considerably. First-wave teachers who attended demonstrations in a demonstration classroom appeared to have the least exposure to the coach's instructional modeling, particularly when coach follow-up on an individual basis was limited. In schools where the coach rolled out the model to teachers individually, exposure to instructional modeling was higher. Model-classroom teachers generally spent the longest time with coaches in their classrooms, and therefore had the greatest exposure to instructional modeling by them. Most teachers received little

8. Note that some coaches modeled in both meeting and classroom settings. additional modeling after the initial demonstration period (coaches were often busy modeling for other teachers), although in a number of cases, teachers said their coaches would continue to come into the classroom to model as needed or at the teacher's request.

As discussed earlier in this report, the importance of instructional modeling rests on the fact that it appears to be an effective teaching tool. Classroom observations conducted by CPRE have established a close correspondence between the fidelity to the literacy workshops structures, as demonstrated by the coach, and the fidelity demonstrated by the teachers who had worked with that coach. Seeing the coach demonstrate in the classroom had an important effect on how teachers subsequently modified their practice, confirming earlier research on coaching and teacher training, and NCEE's rationale for including instructional modeling as part of the coaches' role. On the other hand, the close relationship between coach and teacher fidelity to workshop structures also highlighted the vital importance of the coaches' own skills and understanding of the America's Choice design and instructional goals. This underscores the need for coaches who deeply understand the model and who are committed to instructional modeling in the classroom.

\section{Joint Planning}

In speaking with coaches and teachers, it was clear that some coaches actively involved teachers in planning for the America's Choice workshop lessons while others did not, or were hindered in doing so by the structure of rollout. Joint planning with teachers in a group-demonstration class was clearly more difficult than planning with an individual teacher. In one example, a teacher in a groupdemonstration class complained: 
We haven't worked on things together yet. She comes into my class, does the demo, uses my students, and we ask questions if we get a chance...I don't get a chance to work one-on-one. I feel there isn't enough direction right now... We haven't sat down and had an overview... We do have a chance to ask questions after the demo, but that is all we get right now.

Yet even when demonstrating for an individual teacher, some coaches failed to involve the teacher in planning, relying instead on pure instructional modeling to convey how the America's Choice workshops should be put together. In one such school, a teacher remarked that the coach "was so good [at modeling], she made it look incredibly easy." Yet when the coach left the classroom, the teacher felt completely "lost." In another example, a teacher stated:

\section{It bums me out the way it [writers workshop] was presented. The in-class piece was wonderful, but some of my kids phased out. The language used was too sophisticated for English Language Learner kids. Literacy coaches need to adjust for students and talk to teachers about their kids. I could see where the coach was losing them.}

In contrast, in a number of schools, there appeared to be a lot of joint planning between teachers and coaches. One coach noted:

[It is important for coaches] to work out situations together with teachers, to do lesson plans together. The teacher and coach must become each other's right hand. I'm here to guide, but the coach and the teacher have got to do it together.

Another coach who mainly relied on individual meetings with teachers to roll out the America's Choice model gave the opinion that:
Giving [teachers] the support in terms of doing those model lessons... is important. After those first lessons, I think the meetings are what is important, rather than the modeling...the meetings in terms of planning are important.

In describing her in-class work with the coach, a teacher at another school commented on joint planning:

\section{We worked on presenting writers} workshop to the students. We talked about what literature to use and how to write up the charts. We also asked students to be part of the process. The coach and I decided how best to do this...

Interestingly, with the exception of first-wave teachers attending groupdemonstration classes run by the coach (i.e., demonstrations outside of their own classroom), it did not seem to matter where a teacher fell in the rollout process as to whether coaches and teachers planned together or not. The extent of joint planning seemed to depend much more on coach personality, style, and overall approach to coaching.

\section{Co-teaching}

Another aspect of the in-class coaching that took place in some America's Choice schools was co-teaching. In some instances, the relationship between coach and teacher sounded much more like "peer" than "technical" coaching because both individuals approached the work as co-constructors of the lessons they gave together. A rollout strategy used by a number of coaches (particularly in working with model-classroom teachers) was first to model for a teacher, then to "coteach" the class, and finally to observe the teacher giving the lessons. There was a high degree of overlap between these coaches and those who also practiced joint planning. In one example, a modelclassroom teacher reflected on her coach: 
[She] taught me a lot one-on-one, including setting up my room, explaining the program, showing me the materials, modeling the first few workshops. The first week or two she modeled the first hour, we team taught the second class, and I taught the third class alone.

In another example, a first-wave teacher stated:

We had a really good experience working together. I felt very comfortable with her. I think we could have sat down and worked things out if there had been a problem. We were both very serious about it, but we had fun. The two of us were modeling together. She modeled for me, and together we modeled for them and taught them [the students].

In a number of instances, coaches and model-classroom teachers formed a team, coaching one another as both learned more about the America's Choice model. A model-classroom teacher described working with the coach in what was obviously a joint effort:

We worked on the standards. We focused on writing them for kids to understand. We didn't really work on the genres, not one-on-one. We decided to start on narrative writings. We sat down and read the monographs one day. We also decided together to do the procedures the first week. He would ask my opinion a lot and I would tell him what I thought could use improvement. We were overwhelming the kids at first and we worked together on slowing things down.

Another model-classroom teacher stated that she had initially found it "very stressful" to have the coach come into the classroom and reorganize it, but that over time she and the coach had figured things out together:
And you do have a lot of questions but once you get into it and you see it working, I could do it. And I think [the coach] felt the same way about it, because I don't think she felt comfortable being the knowledge base... There were days when we would look at each other and think, "What are we doing?" But then there would be days when we would think, "Wow! Okay, that was good."

This more mutual, collaborative approach to coaching seemed to occur in two distinct situations. In the first, the coach lacked knowledge or confidence and felt personally comfortable soliciting help from another teacher. In the second, the coach had a "team" or inclusive orientation and felt comfortable and confident enough to give teachers an active role and ask their opinions. Coteaching also seemed to occur more often between coaches and the model-classroom teacher.

\section{Formal Observation and Feedback}

There was a wide range in the study sample between coaches who observed teachers in the classroom every day, and those who observed very little. Several coaches provided an observation period for individual teachers during which teachers taught and the coach observed and gave feedback. Factors that appeared to constrain coaches' observations of teachers included the stage of rollout (those still doing individual demonstrations had less time to observe others), lack of time, teacher resistance, and scheduling conflicts. Most coaches were responsive to requests for observations from teachers.

In terms of frequency of observations, coaches tended to spend more time observing model- and demonstrationclassroom teachers, teachers who were less resistant to the America's Choice 
model (several coaches stated that they observed more where they felt more welcome, not necessarily where the need was greatest), new teachers, and teachers who had just rolled out writers workshop. Teachers tended to be observed and received feedback more often in schools that conducted regular "focused walks" of classrooms. In only a few schools did ongoing classroom observation seem to be a critical component of how coaches defined their jobs; in one school, the coach observed in each classroom at least twice a week on a rotating basis and kept an observation log. Several coaches stated that they felt they should be observing more, but they just didn't have the time and/or scheduling conflicts made it very difficult. Two coaches substituted regular checks on student work and teacher lesson plans in lieu of observations, and gave teachers feedback based on what they saw.

Most coaches gave feedback to teachers based on their classroom observations. While most coaches gave feedback orally, often directly after an observation, some wrote notes and a couple used observation forms or sheets to give written feedback. This was not used for evaluative purposes associated with rating a teacher or contributing to their personnel file. Coaches emphasized the importance of staying positive, being tactful, and thinking about each particular teacher's personality, strengths, and weaknesses. Several coaches said they initially erred on the side of being too "honest" with or critical of teachers, and that teachers felt threatened. According to one coach:

My approach [now] is to try and create openness. I want to make sure they can ask me questions and I want them to like it. If I see something (in an observation) that I really like, I'll leave them a Post-it. If I see a problem, I will discuss it with them. But I try to ask questions about what they were doing rather than come out with criticism.
Another coach also found that asking a lot of questions often led into the teacher's questions and concerns, at which point she felt she had an opening to provide suggestions or additional material. One coach was careful to ensure that teachers understood her feedback to be a suggestion rather than a mandate:

I tell them ahead of time, "I'm going to give you some feedback, and tell you what things you did that were really right on and then give you some suggestions, and even though they're my suggestions, it doesn't mean that they're the end all." And I found that to be very positive for them. I call it collegial feedback... it's not like I'm a supervisor or anything, and usually the suggestions I give, when I go back I see them trying it...

Several coaches found providing formal feedback to teachers to be the trickiest part of coaching, and one for which they felt ill-prepared. In one example, a coach said:

Providing feedback is the toughest part. I want to be considered non-threatening...I would say, "Maybe next time, we'll do this"...I wanted to provide them [the teachers] with opportunities to reflect. I wish I was more adept at conveying information positively.

Another coach mentioned he was uncomfortable with the "policing" aspect of observation, and did not give feedback to teachers on lessons unless they specifically asked for it. One coach felt uncomfortable observing in classrooms and providing feedback because as a fellow teacher (she dropped her coach role when off-track), she felt like she did not have the authority to do so. Moreover, she noted the giving of feedback as an area where her training had been deficient:

I think we need training on effective coaching. I think presenting feedback is something an effective coach needs to be 
able to do. I think an effective coach needs to make teachers feel comfortable, comfortable to get help and receive feedback. America's Choice hasn't provided us with this type of training...

An important question for NCEE is whether the training for coaches should address this topic directly.

\section{Informal One-on-One Coaching}

One of the surprises we found in looking at coaching was how much informal and out-of-class individual coaching seemed to be occurring, and how important that was for teachers. Particularly because formal coach time was perceived to be quite limited, the ability to catch the coach at a spare moment and raise a question or concern was often given as an example of ongoing coach "support" to teachers. This kind of interaction with the coach happened before school, after school, at lunch, at recess, over coffee, in a few minutes of classroom time, or just "walking around." Most often, this type of contact was teacher-initiated, but many coaches also informally checked in with teachers. A demonstration-classroom teacher shared:

[My coach] was asking me today how I felt about what she did during the demo. She gets ideas from me and other teachers during the demo...I would approach her with a problem...we always meet on the playground and we talk a lot.

A model-classroom teacher reported:

I can always talk to [coach] after a lesson... We meet regularly and there is ongoing support; these are not always formal meetings but informal feedback sessions and ways to get resources.

Several teachers stated that the coach had an "open-door" policy with regard to teacher questions, and several also mentioned that the coach would "pop into" their classrooms whenever possible to check in on them. These visits were neither formal demonstrations nor observations, but rather a brief chance for coach and teacher to exchange information and quickly gauge comfort levels and possible needs.

\section{Mentoring}

The CPRE sample of schools included quite a few with a high percentage of new and inexperienced teachers. In these schools, coaches, in effect, doubled as mentors. A few principals regarded this dual function as a particular strength of the coaching model, as evidenced by the following comment:

\section{It provides an opportunity for}

apprenticeship. Half our staff is on emergency credentials...this is an opportunity for half of those teachers to work with a master teacher.

While mentoring a new teacher did not seem to influence the modalities of coaching used (i.e., demonstration, observation, joint planning, co-teaching, and informal contact), it did have an influence on coaching time and content. Several coaches spent additional time with new teachers because they felt it was necessary, and several also felt that working with new teachers was easier than working with veteran teachers because they were more responsive:

I try to work on relationships and everyone requires something different. The more experienced teacher demands more, the newer teachers are easier because they have nothing to compare it to. I find the teachers with 10-plus years of experience are needy in terms of America's Choice... it is presenting a lot of things differently and change is hard for them... the new teachers have to be shown [reading strategies] and need classroom management. 


\section{Reactions to In-class Coaching and Individual Support}

Overall, teacher reactions to the inclass coaching and individual support provided by coaches were positive. This was particularly true with regard to the instructional modeling or demonstration component of the in-class coaching. The fact that the coach demonstrated writers workshop in the classroom was seen as enormously helpful to the overall understanding and implementation of the America's Choice design. Several teachers who had received little modeling expressed the desire for more. Interestingly, many teachers had positive reactions to the instructional modeling even in cases where they were more broadly critical of the coach and/or the America's Choice program, materials, or design. Some examples of reactions include:

A strength of this coaching strategy is the fact that teachers have a model to work towards. Being able to watch someone demonstrate how the workshops should be taught is an invaluable way to learn how to implement the America's Choice workshops...

-Principal

[The modeling was] very helpful. It was hard for me to grasp what it was at first, but to see someone do it, it just puts the things that you read together...it just makes so much more sense.

-Model-classroom teacher

Nonetheless, there were some important caveats about instructional modeling that came through in several of the responses. A couple of teachers confessed to at least initially finding the coach coming into the classroom to model as "intrusive." This reaction was particularly strong in situations where the coach had not taken the time nor had the opportunity to sit down and plan with the teacher prior to coming into the classroom. The pace and timing of rollout also affected teacher perceptions of the usefulness of modeling. Several teachers mentioned that it was hard to have the coach come into their classrooms to model (or introduce America's Choice materials) later in the year, once they had already gotten to know their class and established their own rituals and routines. Unfortunately, given the America's Choice training schedule for coaches, it was not possible for coaches to begin rollout to most teachers at the beginning of the year.

Several teachers were also keenly aware that the modeling they had received was only as good as the coach as one model-classroom teacher noted:

I think if the right people do the modeling, then I would have so many positive things to say about it. [Her first coach] didn't do a great job. She is a teacher, not a coach. She has classroom management difficulties. She couldn't control the class. She could be really good, and I got a lot out of her being in my class, but other people could do it better.

A second teacher pointed out that, although the coach talked about standards a great deal in meetings, the lesson she modeled for her that day had not incorporated any reference to standards. A teacher who appreciated the in-class coaching exclaimed:

I must say that this is the first time in 32 years that I have someone in class with me who knows what she is doing!

Coaches and principals, although very positive about the modeling overall, also raised some concerns, including those about teachers who viewed the modeling as "free time" for themselves, rather than an active and participatory 
learning opportunity, and the risk of creating teacher dependency on the coaches. According to one coach:

I never did take over a classroom to completely model or demonstrate. I worked with teachers; I did model lessons. I believe that teachers have to take ownership early on or they will not implement it. They will continue to rely on the coach. I learned this from problems other coaches were describing at the coaches' network meeting.

This risk of teacher dependency on coaches also came through in teacher responses to a question about how teachers determined the source of a lesson on any particular day. Quite a few teachers expected the coach to provide the lesson or lesson ideas, although it should also be noted that several of them were still at an early stage of implementing writers workshop and were working with the model lessons provided by America's Choice.

Teachers who had done joint planning or co-teaching with their coaches were generally more positive about their coaching experience and the America's Choice model overall than those who had not. It also seemed that frequent informal contact with coaches went a long way toward making teachers feel supported and increasing their general comfort level with the America's Choice workshops. Teacher reactions to feedback from coaches were more difficult to discern, but of those teachers who specifically mentioned coach feedback, most found it positive and helpful. One model-classroom teacher thought more feedback and constructive criticism from the coach would have been helpful. In general, teacher reactions to coach feedback appeared to be subsumed into the larger issue of how supportive they found their coaches.

\section{Summary}

Coaches employed a number of different techniques that fell under the term "technical coaching" when providing in-class and individual coaching support to teachers. These included: instructional modeling, joint lesson planning with teachers, co-teaching, formal observation and feedback, informal one-on-one contact/conversations, and mentoring of new teachers. While almost all coaches did some instructional modeling (as mandated by the coaching model), the extent to which they employed other techniques varied considerably. Factors that appeared to influence a coach's use of these techniques included the structure of the school and rollout, time, experience and personality of individual teachers, coach personality, and perception of the coaching role. Teacher reactions to the in-class coaching were generally very positive, more so when the coach engaged in joint planning or co-teaching and was perceived to be available for frequent one-on-one contact.

\section{Group-focused Professional Development Activities at America's Choice Schools}

Group-focused professional development activities were an important component of the America's Choice model and of the rollout process for most Cohort 4 school sites, but again, these activities did not always parallel the structure prescribed by NCEE. Further, these activities not only differed from those set by NCEE, they differed across states, districts and schools. The scheduling of group-focused professional development activities were often influenced by state, district, or school policy that determined how and when these meetings took place. 


\section{Group-focused Professional Development}

\section{Teacher Meetings and Study Groups}

According to interview data, all of the schools held teacher meetings. ${ }^{9}$ However, teacher meetings differed in format from one school to the next, and rarely did teacher meetings follow the timetable or guidelines recommended by NCEE.

Many schools used already established meeting times (e.g., grade-level meetings, psyco-motor time, department meetings, house meetings) to conduct teacher meetings. As such, the frequency of teacher meetings did not correspond to the eight teacher meetings outlined by NCEE. Most schools reported holding teacher meetings either weekly or twice monthly. Holding teacher meetings more frequently than prescribed did not, however, provide assurance that the content to be addressed in NCEE's suggested framework of meetings was covered and/or understood by those attending. Using the example of the suggested topic and purpose of teacher meeting \#1 ("Conferencing"), it is interesting to note that in a few schools, teachers and literacy coaches reported that they did not address the monographs in teacher meetings (the literacy coaches in two schools reported not having any knowledge about the monographs at all). The discussion and presentation guide for

9. Interview data collected from teachers, coaches, and principals regarding group-focused professional development activities (teacher meetings and study groups) conflicted at times. Perhaps due to a lack of understanding regarding the definition of a teacher meeting versus a study group, one source of information from a school site would report contradictory information regarding the scheduling or availability of group-focused professional development activities. In these cases, interview data were reviewed to determine which source(s) of information should be reported. Observational data of group-focused professional development activities were not collected. teacher meeting \#1 prepared by NCEE, however, revolves around the monograph entitled Writing Conferences. Though clearly teachers could grasp the concept of conferencing without referencing the monographs, and a literacy coach could teach the concept without adhering to the discussion/presentation guide, it is difficult to imagine a case wherein adherence took place without some reliance on the monograph mentioned.

While teacher meetings were reportedly taking place in all schools, study groups were taking place in only 5 of the 27 schools we visited. Most schools reported that study groups were not held, and many teachers and literacy coaches confessed to lacking knowledge of the study group structure and/or purpose. But many of the teacher meetings described by teachers and literacy coaches fell closer to the researchers' understanding of a study group than a teacher meeting.

For example, teacher meetings were described by many teachers as a place where information is provided and discussed. Many teacher meetings (especially when held on a weekly basis) lacked the data-driven and action-focused characteristics that distinguish these meetings from study groups. Teachers brought student work and analyzed data in some teacher meetings, but not consistently in all teacher meetings. Teachers and literacy coaches reported that teacher meetings resembled what we consider to be a combination of teacher meetings and study groups. In other words, teachers, coaches, and principals used the term "teacher meeting" to reference many of the activities NCEE would define as a "study group." In one school, for example, the teacher explained that teacher meetings were held twice a week and covered standards, materials, the use of folders, mini-lessons, and monographs. Some of these are topics to be covered in study groups. This same 
teacher, however, stated that her school did not hold study groups. Other teachers made clear that they did not understand the distinction between the two types of meetings:

[We have] teacher meetings once a week by grade level. We do professional development and America's Choice planning and the coach presents us with readings and writing techniques. We can ask questions based on classroom instruction experiences.

There are no study groups that are distinct from the grade-level teacher meetings or school staff meetings.

The lack of reported study groups in many schools may be due to a shortcoming in understanding the distinctions between these distinct group-focused professional development activities. Most teachers reported attending groupfocused professional development activities covering a range of topics.

\section{All-staff Meetings}

All-staff meetings were easier for teachers, coaches, and principals to identify. All schools reported holding allstaff meetings, and, in most cases these meetings reviewed the content prescribed by NCEE. These "whole-school" meetings were often run by the principal, and focused on "more general" America's Choice items. Because all-staff meetings discussed topics in addition to those pertaining to America's Choice, and were often run by someone other than the literacy coach, a number of teachers and literacy coaches reported that these meetings were not as informative or as helpful as teacher meetings or study groups. Further, many teachers complained that the large size of these meetings - attendance by the entire staff lessened their opportunity and ability to gain new knowledge.

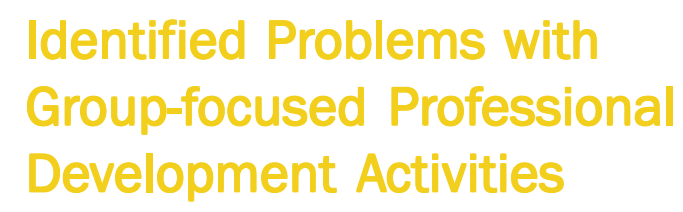

As discussed earlier, the America's Choice coaching model places literacy coaches in a pivotal role while they are often just one step ahead of the teachers in terms of their knowledge of and experience with the design. While most teachers found the group professional development activities to be useful, many teacher complaints reflected a lack of faith in the coaches' knowledge of America's Choice. Teachers who felt that group-focused professional development activities were "a waste of time" often had complaints about the person leading these activities. ${ }^{10}$

Some teachers also felt that while their literacy coach was well-qualified to work with students in demonstrations or in a model classroom, the coach did not have the experience or qualifications to effectively lead, manage, organize, and teach teachers. This perception reinforced teachers' beliefs that in-class and individual coaching was more useful than group-focused professional development activities. A principal at one school identified overall reliance on the literacy coach as a problem and suggested that NCEE provide direct training to teachers as a means of lessening this dependence on the literacy coach.

Another difficulty identified with group-focused professional development activities was related to the sequence and content of the teacher meetings and how that was sometimes out of sync with

10. A few teachers and literacy coaches stated that meetings run by individuals other than the literacy coach were inferior than those administered by the literacy coach due to lack of knowledge or experience. As an example, one teacher reported, "The meetings run by the coaches help supplement the classroom piece. The meetings run by the principal add to the confusion." 
where a teacher fell in the rollout process. Teachers and literacy coaches believed that group-focused professional development activities made little or no sense when a teacher had not yet received any in-class technical coaching. This situation presented teachers and coaches with some discontinuities or mismatches of information provided in one venue and not reinforced or reviewed in the most essential location - the classroom. Both coaches and teachers identified and discussed the problem of teachers at different stages of implementation attending the same group-focused professional development activity:

We have been working on rubrics and standards [in teacher meetings] and they [some teachers] don't think it is related to America's Choice. Maybe it is because we haven't started doing it on our own that it is hard to see the connection. Maybe when we get going it will become clearer.

Teacher meetings complement what goes on in the demos. It would be ineffective without the demos. And, I think teacher meetings for those who haven't rolled out increases their frustration level - they should be excluded [from teacher meetings].

The problem is that so many teachers haven't had the in-class coaching that the two don't fit for many teachers.

This sequencing problem had the effect of diminishing both the informative/instructive role of these activities and the "supportive" role identified by teachers.

A third problem discussed primarily by literacy coaches was the lack of principals' support for the model, in general, and for group-focused professional development activities, in particular. A number of literacy coaches stated that the principal had to support these activities, encourage attendance, and provide "trust":
...I think the relationship had to be one of trust...That can be a big issue between a coach and a principal. And that is something I feel that is lacking to some extent in the program... For it to be successful, the coach needs tremendous support from the principal in terms of time resources, and understanding the complexity of what is required.

Some principals cited the provision of time and space for group-focused development activities as a major means of support for the program and for the coach.

\section{Summary}

Teachers in America's Choice Cohort 4 schools were meeting on a regular basis - whether in study groups or in teacher meetings, and/or all-staff meetings. In many of the schools, teachers, literacy coaches, and principals met on a more frequent basis than recommended by the overall design. Nonetheless, there was substantial deviation from the America's Choice model in terms of the content and focus of such meetings as well as the terminology used to describe them. Most teachers, for example, stated that there were no study groups in their schools.

According to interview data, most teachers felt that group-focused professional development activities were useful. Yet, teachers also made it clear that some meetings were more useful than others, and that their position in the rollout sequence at their school had an impact on their perception of the utility of these meetings. Teachers who felt that the meetings were far less useful than the inclass demonstrations tended to feel either that the meetings and demonstrations were not well connected, or that the coach was far more competent at demonstrating than at doing the kind of staff development that the meetings were supposed to facilitate. 


\section{The Influence of Coaching on Standards-based Instruction}

A persistent concern that emerges from CPRE's research on the coaching model in America's Choice schools is the role coaching may or may not play in getting teachers to implement standardsbased instructional practices within the structures of the literacy workshops. The structures of the literacy workshops are the starting point, and a delivery mechanism, for the desired instructional approach that is the ultimate goal - standards-based instruction. The connections coaches make for teachers between the technical coaching portion of the model and the group-focused professional development activities can lay the groundwork for a standards-based instructional approach if teachers and coaches clearly identify the overlap between the two distinct activities, link them to the standards, and build upon them to reach the goal of standards-based instruction. Certainly this is a multi-year process, and the schools we visited were likely to be in the preliminary stages since they were in their first year of implementation. Nonetheless, conversations about making instruction more standards-based should be ongoing among coaches and teachers.

\section{The Content of Coaching: Where do the New Standards Performance Standards Fit In?}

In interviews with teachers and coaches, we asked a general question about what they had worked on in class and in meetings, as well as follow-up questions regarding the use of America's Choice monographs on writers workshop, the America's Choice genre studies materials, and the New Standards Perfor- mance Standards. Since effective professional development necessitates showing teachers how to connect their work to specific standards for student performance, the New Standards Performance Standards must be central to these activities. Additionally, the America's Choice monographs and genre studies were developed to assist teachers in deepening their understanding of the America's Choice approach, and, according to the coaching model, these materials should be addressed in group-focused professional development activities.

\section{Monographs and Genre Studies}

Most teachers stated that they had worked with the coach individually and/ or in class on setting up the classroom and on at least some aspects of the basic structure, rituals, and routines of writers workshop. Most teachers were also familiar with the America's Choice monographs that describe the different pieces of writers workshop, although initial exposure to the monographs most often took place in a meeting or workshop setting with the coach subsequently modeling the different pieces in a classroom setting. In the words of one coach:

[I] address the monographs through [group-focused] professional development, like the sourcebooks, what they are, what goes in it... Every teacher has a genre book with the lessons laid out for them in it.

Middle school teachers' familiarity with America's Choice genre studies materials was more limited, and those teachers who had actually worked on the genre studies with a coach in the classroom were fewer still, a fact that may be reflective of the slower-than-anticipated rollout in many schools:

We have addressed the monographs in teacher meetings and we have included the monographs in a series of 20 lessons that we pass out to the teachers every six 
weeks. We haven't tackled the genre studies at all...

Group-focused professional development activities, according to interviews, played a critical role in providing teachers with information on both genre studies and the monographs, but did not necessarily achieve widespread adoption of this content by teachers in their lesson planning.

\section{New Standards Performance Standards}

With regard to the New Standard Performance Standards, most teachers were familiar with at least some elements of the standards, either through having them discussed in meetings, or modeled in the classroom. According to interview data, some coaches clearly placed a lot of emphasis on demonstrating how to use the New Standards Performance Standards in the classroom, while others did not. According to one coach:

\section{During the demonstrations, I did this [modeled the New Standards Performance Standards] every day...the New Standards Performance Standards is the basis of the entire rollout. I get all my inspiration from the New Standards Performance Standards.}

A teacher who had worked with this coach confirmed that although they had covered the New Standards Performance Standards in meetings, "We mostly went over standards in class...for example, with narrative writing he pointed out the elements of the standards to focus on. We would take it apart."

In contrast, another coach stated that her co-coach "covers the New Standards Performance Standards in staff development, but it really isn't modeled. I don't model that."
In all but two of the schools, teachers, coaches, and principals reported introducing and/or reviewing the New Standards Performance Standards in groupfocused professional development activities. At least in some cases, teacher meetings also provided the opportunity to discuss and analyze New Standards Performance Standards-based work going on in the classroom.

There were indications in both interviews and classroom observations, however, that both coach and teacher comprehension and use of the standards was limited. One teacher confessed that, "I'm not sure we fully understand what standards are, but it is starting to make sense." A coach acknowledged that her teachers needed more work in this area:

With the New Standards Performance Standards, they have to be incorporated into teacher lesson planning. I am probably a little weak on standards myself. For example, what I see in the rooms is the personal narrative standards are posted, but it is in teacher language, and teacher language and student language are distinct. In the primary grades, we need to see the elements of each standard bullet a writing lesson that addresses each standard.

While most principals articulated a solid understanding of the centrality of the New Standards Performance Standards to the America's Choice design, most were aware that some teachers were still struggling to understand the standards. In one school, the principal estimated that about half the teachers were "getting it." Two other principals commented:

Teachers are still learning the standards and some of them are slow learners they can't figure them out. They think they are different from the state standards...We discuss the New 
Standards Performance Standards during both of these times [group-focused professional development], but some teachers are getting it and others are not. Working with standards is a new process for the teachers. Real understanding of standards and rubrics will take another year. It will take a lot of modeling and review.

Some are, some aren't [understanding the importance of the New Standards

Performance Standards] - it is about 50/ 50.

Principals pointed out that groupfocused professional development activities are critical to increase teachers' understanding of the New Standards Performance Standards. Teachers and coaches concurred that the New Standards Performance Standards were often discussed in group-focused professional development activities and deepened their understanding of standards. All parties, however, indicated that time was an important variable in increasing teacher understanding of standards. It is reasonable to expect that, with time on task, teachers will gain a deepened and nuanced grasp of what standards-based instruction looks like. A lingering question, however, is to what extent teacher knowledge is dependent on the coach's own mastery of standards-based instruction.

\section{Fidelity to Literacy Workshop Structures as Vehicles to Deliver Standards-based Instruction}

As discussed above, interview questions with teachers, coaches, and principals about the New Standards Performance Standards indicated some unevenness of understanding during this first year of implementation. As a complement to the interviews, CPRE conducted classroom observations of coaches and teachers implementing the literacy workshops in the schools. Teachers and coaches were rated on where they fell on a four-point scale designed to indicate fidelity to the literacy workshop structures. This scale enabled CPRE researchers to gain an idea of how much of the skeleton of the literacy workshops was in place since these structures provide the framework from which to develop a standards-based instructional approach.

One key point to take away from CPRE's report, Implementation of the America's Choice Literacy Workshops is that it is necessary to distinguish between teachers and literacy coaches who simply comply with the basic structures of the literacy workshops and those who understand the possibilities that fidelity to the model can bring. There are a variety of teaching and learning opportunities that fidelity unleashes and these are explored in more detail in that report. Other key points that surface in this report are that teachers were most likely to closely model the level of fidelity to the structures that are demonstrated to them by their coach in their school. This was consistent across all three levels observed in the schools: early elementary, upper elementary, and middle school observations. This finding affirms the centrality of the role a coach plays in a school in terms of modeling the structures and instructional techniques that teachers are expected to adopt in their classrooms. As a result, the importance of training the coach properly so that teachers, in turn, may be trained according to the specifications of the design cannot be underscored enough. Additionally, those coaches who referred to standards in their demonstrations to teachers increased the likelihood that teachers would carry that practice over into their work with students. 


\section{Critical Connections Between Group-focused Professional Development Activities and Technical Coaching}

In order for standards-based instruction to develop and evolve, the existence of connections between the array of professional development activities is essential. In effect, standards-based instructional practices are in great measure contingent upon the connections teachers and coaches make between technical coaching and group-focused professional development. These activities provide the venues for the discussion of the standards among teachers and coaches, and the eventual development of professional learning communities. There are implications for the connections made, or the lack of those connections, in terms of how readily standards-based instruction moves forward in a school.

\section{Comparing and Connecting Approaches to Professional Development}

Teachers, coaches, and principals in the schools in our sample were able to articulate a critical connection between the various group-focused professional development activities held at their school and technical coaching (in-class and individual coaching). Most teachers, coaches, and principals felt that both forms of professional development activities were essential components of the model:

Both are needed - they go hand-in-hand. Both have contributed to my comfort level. I couldn't do it with just coaching or with just the teacher meetings couldn't do it without both. They are equally needed. They target two different areas.
Teachers, coaches, and principals also considered group-focused professional development activities important because of their parallel connection to the in-class technical coaching focused on instructional practice. A number of literacy coaches reported that teachers' classroom needs influenced the topics covered during group-focused professional development activities. This two-way flow of information was meant to deepen teachers' understanding of America's Choice design and content by analysis of student work as well as teachers' needs.

Everything covered in teacher meetings is coordinated with something that has been done or will be done in the class - they have to be connected.

They parallel each other - they go over the same things... We go into more depth in teacher meetings... the coaching piece is about me.

Everything that we talk about, we try to make sure that it relates to something they can do in the classroom.

Nonetheless, many teachers and literacy coaches indicated that groupfocused professional development activities did not play as crucial a role in their ability and preparation to implement the literacy workshops as the technical coaching piece. Instead, group-focused professional development activities occupied the position of a reinforcing activity, a complement to the technical coaching work done in an individual classroom. One teacher offered the opinion that teacher meetings did not contribute to her comfort level in implementing the America's Choice literacy workshops because she had already received in-class training and had implemented the lessons modeled for her in the classroom. Other teachers reiterated the value of instructional modeling in the classroom by placing an emphasis on the importance of the individualized contact with the coach: 
In-class coaching is much more useful to me. Teacher meetings often turn into $Q \mathcal{E} A$ and that isn't productive for everyone.

If she [coach] never came into the classroom, it [professional development] would not be as effective.

Many respondents felt group-focused activities were supposed to provide "support," or to "supplement" the inclass technical coaching piece, and could not work as a stand-alone professional development tool.

The meetings mostly supplement and inform and in that sense they are useful and contribute to the comfort level [in implementing].

Therefore, many teachers acknowledged that they considered the technical coaching piece to be more useful and "central" to their ability to implement the model in their classrooms.

[In-class] coaching is indispensable. I couldn't have done it without the demonstrations...teacher meetings have helped a bit in my comfort level implementing writers workshop in my class, just not as much as the in-class coaching.

\section{Creating Professional Learning Communities}

Many teachers and coaches felt the primary role of group-focused professional development activities was sharing and support; the acquisition of new knowledge and techniques was viewed as a secondary function. Teachers reported that sharing information and ideas with other teachers was a critical component and a principal reason why they valued group-focused professional development activities. This might be an early indicator of the creation of professional learning communities in America's Choice schools.
The other teachers in meetings, they are my support, my backbone. I get a lot from other teachers in my grade-level meetings.

Teachers compare experiences... and you will try something and say, "This is what I tried and either it worked or didn't work"...And they'll say, "That's okay, that's all right" or "Well, maybe why don't you try it like this"...

...meetings are valuable because you can share ideas and plan. It benefits the students and it helps us. Many heads are better than one, and it does make me feel more comfortable in class, but not like modeling.

A few teachers stated that they would find a way to meet informally with other teachers outside of teacher meetings (i.e., in the lunchroom, on the playground, in the hall) because of the value they placed on these exchanges. Overall, many teachers felt a constant source of support from both the literacy coach and from peers through group-focused professional development activities - a "continuation" of the in-class technical coaching piece.

\section{Summary}

Interviews with teachers, coaches, and principals indicated that the understanding and use of the New Standards Performance Standards in planning for instruction, as well as supplemental America's Choice materials (specifically the writers workshop monographs and genre studies), is still at an early stage. While this finding among teachers is not surprising given that all schools were in their first year of implementation, the fact that coach understanding and use of standards also varied considerably is an issue of greater concern. CPRE's classroom observations indicate that teachers' ability to faithfully reproduce the structures of the literacy workshops closely tracks that of their coaches; if one makes 
the large but not unreasonable assumption that closer fidelity to structure also implies a more standards-based approach to instruction, then the coach's knowledge of standards and ability to model standards-based instruction in the classroom may have a strong effect on teachers' ability to do the same.

Although teachers, coaches, and principals for the most part saw a connection between the in-class technical coaching and group-focused professional development elements of the coaching model, teachers' perception of teacher meetings as a source of "support" and as "supplemental" versus "primary" could also be a cause for concern. If groupfocused professional development activities are the primary means to create professional learning communities in America's Choice schools, they are serving that purpose. However, if these activities are one of the vehicles for teachers to capitalize on the connections between what gets discussed in these meetings and classroom instruction, then teachers and coaches may need more guidance and assistance from America's Choice on how to maximize the utility and connection of these activities to standards-based instructional practice and the broader design. Ironically, as mentioned earlier in this report, the very detailed guides for teacher meetings and study groups developed by America's Choice did not seem to be in use in most of the schools visited.

\section{Summary of Factors that Influenced Coaches' Implementation of the America's Choice School Reform}

While this study was not designed to measure the effectiveness of individual coaches, we were able to draw on our data to compile a list of factors that seemed to influence coaches' effectiveness in implementing the America's Choice model. There are two kinds of information from school visits that can be construed as indicators of effectiveness. The first is a review of responses from teachers and principals as to how they valued the work of the coaches and what features they particularly appreciated. These data are somewhat subjective, but there are sufficient patterns among the responses to suggest some preliminary indicators of coach effectiveness. The second type of information is more objective. How successful were the coaches in rolling out the reform elements and workshops in the schools? And in doing so, was there reasonable fidelity to the model? By examining these two types of data, we were able to gain insight into a set of factors that influence coaches' effectiveness in implementing the America's Choice model. Each of these factors is discussed below.

\section{Human Relations Skills}

One of the most frequently cited factors as a facilitator or barrier to coach effectiveness was the human relations skills of the coaches, and their individual personality or approach to coaching. Overall in the interviews, there seemed to be almost more concern about process than content and expertise. This emphasis on personality may reflect the assumption that teachers will not change their practice or listen to coaches (no matter how good) if their personalities are offputting. Coaches relied on human relations skills to soothe, persuade, and get teachers comfortable enough to adopt the America's Choice model. The importance of these qualities or skills was mentioned repeatedly by coaches and principals (with teachers it tended to be rolled into whether they felt "supported" and whether they considered the coach "approachable"). Coaches who were friendly, funny, diplomatic, thick-skinned, flexible, and went out of their way to 
make teachers feel like they were being listened to or made part of a team, seemed to have fewer resistance problems than those who did not. An important consideration, however, is whether these skills are innate, and what skills can be taught, and might therefore be an appropriate focus of coach training.

\section{Coach Accessibility}

Coach accessibility was of great importance to teachers (as reflected in their interviews) and had considerable influence on the degree to which they felt supported and comfortable in implementing the America's Choice literacy workshops in their classrooms. Coaches who had an "open-door" policy or went out of their way to check in with teachers on a regular basis were generally perceived more positively.

\section{Individual Interaction with}

\section{Coach}

Teachers' ability to have individual interaction with the coach, even if brief and informal, also seemed particularly valued by teachers. Teachers who had worked with the coach individually in their classrooms often cited this experience as the most effective part of America's Choice professional development.

\section{Inclusiveness}

Teachers appeared to be more positive about coaches who solicited their opinions or who had included them in either joint planning or co-teaching of America's Choice workshops. An inclusive approach by the coach both served as a leveler (establishing the coach as a colleague rather than a supervisor) and a confidence builder for teachers. In the words of one model-classroom teacher:
The coach made me feel like I was part of a team. He would have teachers go into my class and observe. I felt I really knew what I was doing. He made me feel good about that.

\section{Timeliness and Relevance of Information}

Quite a few teachers complained about the timeliness, consistency, and relevance of information they received from their coaches concerning America's Choice. In many cases these complaints appear to be related to the coaches' training schedule which took place at several points in time during the school year. Some coaches appeared more skilled than others in organizing the content of the meetings in such a way that teachers felt that the information directly reinforced what they were doing in the classroom. In particular, the needs of those teachers already implementing America's Choice workshops in their classrooms appeared to be quite different from those of teachers who had not yet started implementation.

\section{Flexibility and Willingness to Innovate}

An indicator of coach effectiveness mentioned in interviews was the coach's willingness and ability to adjust the model to local circumstances. For example, one principal praised her coaches for the extensive "scaffolding" work they had done in order to make the literacy workshops work with an English Language Learner population. On the other hand, too much of a departure from the model raised fidelity issues and the question of whether America's Choice workshops were being implemented at all. 


\section{Teacher Resistance}

For principals, an important indicator of coach effectiveness seemed to be how much resistance the coach encountered or generated in the course of rolling out the America's Choice workshops in the school. The importance of coach "personality" echoed throughout interviews with both principals and coaches. The underlying assumption appeared to be that if the coaches were not able to get teachers on their side, it did not matter what they told them or how good they might be. For principals, a large group of unhappy teachers also constituted an administrative headache. In one example, a principal stated:

Personality and presentation make a difference. You have to be flexible and not take things personally. And in this school almost half the teachers she [the coach] works with have not bought into the project. She's not communicating with them very well.

\section{Understanding of Literacy Workshop Structures}

As discussed in Implementation of the America's Choice Literacy Workshops, the CPRE study included classroom observations of coaches and teachers implementing the literacy workshops, and a subsequent rating of how faithful these were to the America's Choice model. These analyses showed that there was a high degree of correspondence between the coaches' fidelity to the America's Choice model, and the fidelity demonstrated by those teachers who the coach instructed. This is a particularly important finding because if fidelity of implementation is a desired outcome, these analyses support how central the coach's role is to achieving that goal. In other words, teachers are unlikely to implement workshops according to the model unless the coach's modeling is also faithful to the model.
The more faithfully the coach adhered to the workshop structures, the more faithful teachers were likely to be, although there were some exceptions. If an observation of a coach indicated little fidelity to the model, it might follow that America's Choice literacy workshops would not be implemented in the intended manner by all teachers in that school.

\section{Background and Experience of the Coaches}

Different aspects of a coach's background and experience appeared to act as facilitators or barriers to coach effectiveness. Some coaches reported that they thought having an administrative or instructional support background was helpful to them in their coaching because they already had some experience supporting adults. Prior experience in the school building or having been selected by the principal (and staff) also seemed to give coaches a slight advantage. In Georgia, being an "outsider" seemed to place an additional burden on the coach, especially since principals were not involved in selecting the coaches who were assigned to their school by the state. On the other hand, coaches' prior experience as a colleague of teachers in the school was double-edged. In several cases, this experience was reported to be helpful because the coaches already had a rapport with teachers and were liked or respected by them. Yet in other cases, it strained some relationships as the coach moved into a new role in which they were no longer seen as peers or colleagues, but were considered to be more of an administrator or supervisor. Mastery of subject knowledge and teaching skills were two areas mentioned by both principals and coaches as being important to coach effectiveness, although as mentioned earlier, only rarely was there a specific reference to the importance of expertise in either literacy or standards. 
The limited exposure of coaches to either balanced literacy or standards-based reform prior to implementing America's Choice can be seen as a significant barrier to coach effectiveness and a particular challenge for NCEE training.

\section{Degree of Administrative Support and Involvement}

The amount and type of support provided to the coach by the principal appeared to be a critical facilitator or barrier to coach effectiveness. There were a range of situations documented by CPRE in the school visits: the principal was not supportive of the America's Choice model or coach, the principal was supportive of the model but not the coach, the principal had a good relationship with the coach but was not supportive of the model, and the ideal situation where the principal was supportive of both the coach and the model. The more the principal took ownership of the America's Choice model, worked to understand it thoroughly, and translated that ownership into specific school-level action and follow-up with teachers, the easier the coach's job appeared to be.

Most principals recognized the need for a strong, collaborative relationship and good communication with the coach in order to make the America' Choice model work. Beyond good communication and recognition of the demands of the model on the coach, several principals' involvement in the implementation of America's Choice workshops went further. In one school, the principal organized and ran the focused walks, and designed a rubric for use on the focused walks and as feedback to the teachers. In another school, the coach ran teacher meetings, but the principal always attended the meetings and was briefed on the content because of the "need to be able to back her up." This same principal stated:
Teacher meetings are participatory. I want to hear from every teacher. The one teacher who hasn't participated has asked for a transfer. She says she is doing this or that, but can't back anything up. The teachers need the New Standards Performance Standards for their plans and they need to be able to discuss it. If they can't, I know they aren't doing it. I make sure that the standards and the task go up on the wall. You can see work isn't focused when the task goes up first instead of the standard first. The work is so different.

This example indicates both a sophisticated understanding of the America's Choice instructional goals and a high degree of follow-up on those goals within the school.

In quite a few cases, however, there was a division between how principals described their support of coaches versus how the coaches perceived the principal's level of support. Two comments by coaches about the principals in their schools are illustrative (note that these do not correspond to the principals of schools quoted above):

I don't think he believes in America's Choice. He talks the game but I don't believe it. He's never been in classrooms when I have been there. It was his job [according to NCEE] to present the modules on the standards to the teachers. They took him for training on presenting the standards. The teachers didn't understand it and I had to do it over again later. There is some conflict on what he is given and what I am given from NCEE and that is not good. There is some resistance in the school about America's Choice and I think he divided the faculty.

I think [the relationship] requires the principal having the instructional background, and really having a grasp of the concepts we're required to fan out to people, and also kind of patience to know 
that it's not going to be rolled out the same to everyone because everyone internalizes things differently. It's been kind of hard with my particular principal because that hasn't been the case...so a lot of it has been almost like the blind leading the blind...

Yet even when principals were supportive of the coach and the model and deeply involved in implementation, style seemed to make a difference. As mentioned earlier, principal rebukes of teachers for non-adherence to the America's Choice model appeared to increase teacher resistance to the coach in at least two schools that CPRE visited. In both cases, the coach was seen to have failed to communicate expectations sufficiently prior to the principal's heavy-handed follow-up with teachers.

\section{Sufficiency and Timeliness of NCEE Training}

There were numerous complaints about the timing of NCEE training, and the difficulty of rolling out a model when coaches felt they did not yet understand it themselves. According to both coaches and principals, training happened in bits and pieces and coaches felt like they were only one step ahead of teachers. Many coaches felt like they needed to have begun their training well before the start of the school year. A few principals expressed the view that it would be better to have NCEE train all teachers, and have coaches as backup. Several coaches also raised the issue of conflicting information arising from principals' and coaches' training, and the need to have everyone on the same page, with similar expectations, from the beginning of rollout. In terms of the content of training, coaches mentioned that their training should not assume people have a balanced literacy background, and felt that training and materials did not cover certain key issues. These included: how to deal with English
Language Learners and special education students; "change management" training, including how to deal with teacher resistance, motivation, and team building; more training on basic knowledge about writing; and more training on effective coaching, including providing feedback to teachers. Two coaches were unclear about whether NCEE was planning to provide additional model lessons, and did not seem confident about implementing the workshops without additional instructional materials.

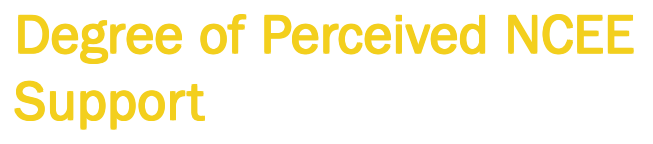

Most coaches believed that the level of ongoing support from NCEE and regional personnel was adequate to good. Coaches in Georgia had the strongest institutional support, with team leaders habitually visiting the schools once a week. Coaches in Georgia had also formed support networks among themselves. One coach in Georgia expressed her overall satisfaction with this multilayered network of support as follows:

I couldn't ask for better support. The first line of support, when I need help or have questions is the team leader who is in charge of the six schools in this county. I also get support from peers in the [literacy coach] network meetings and through email. Our regional director is a good business person but never loses sight of the fact that we are working with children.

Coaches in schools outside of Georgia most often saw cluster leaders once a month. According to one coach, contact with NCEE on a monthly basis was not a sufficient level of institutional support to implement the model:

I am not happy with the support we have received. That to me is the weakest part of the program. They [NCEE] need to be 
staff developers and not just a person who comes into the school and chats. We need more substantive and extensive contact with the cluster leader. I need something to be modeled for me, to redirect something that needed correction in a professional development session. In the same way that I would at the school level with the teachers, we need NCEE to work with us. In the building once a month is not enough to do something so monumental in a school.

Support also depended heavily on the skills, personality, availability, and commitment of cluster leaders. While some cluster leaders appeared to be working overtime to meet school needs, one school stated they "basically never saw" their cluster leader. Several coaches noted that NCEE trainers had given out email addresses and phone numbers, but there was hesitation on the part of the coaches in contacting them as they were perceived to be very busy. One coach found trying to get help from NCEE staff to be particularly confusing, remarking, "It's nobody's department" and "Seems often that the right hand doesn't know what the left hand is doing." Some coaches resented the fact that cluster leaders were given information that was not necessarily shared with them, and viewed this information gap as impairing their ability to perform all their tasks. The degree to which communication from NCEE was coherent and credible was an issue for a number of coaches and principals.

\section{Perception of the Coaches' Role: Issues and Uncertainties}

Perhaps one of most important factors that impinged on the coaches' ability to be effective was one that may be hardest to resolve. That is, the ambiguity of the coach role and the uncertainty of what the relationship should be to the teachers, the principal, and the leadership team.
How much initiative can a coach take? How much flexibility is there in the implementation process? In what ways is the coach accountable and to whom? Both prior experience and individual personality have factored into how the coaches addressed these issues, but for a majority of coaches the stress of these concerns has taken a toll. A key question we pose is how can NCEE provide support in this area and better prepare the coaches for the role? How can the expectations for the role of coach be shared with teachers and supervisors?

\section{Time}

If one was to ask America's Choice coaches what they thought was the single most significant barrier to effective coaching, they might answer "time." The overall lack of coach time was a powerful theme across both coach and teacher responses. Coaches were pulled in many different directions. In some schools, principals recognized the problem and tried to give them fewer administrative duties. In other schools, coaches still wore multiple hats and were struggling under the weight of their numerous responsibilities. The problem seemed particularly pronounced at the middle school level, where there is one literacy coach rather than two. Contributing to the lack of time were a number of external barriers multiple programs taking place at the school, the track problem in California, and the relentless focus on testing that led to coaches frequently getting pulled away from America's Choice rollout in favor of test preparation. In addition, NCEE training during the year also required coach time on a regular basis, which in turn affected the pace of rollout.

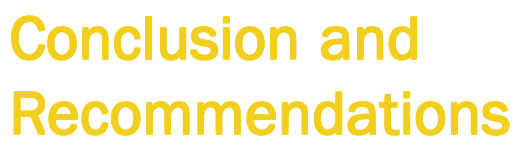

The America's Choice school model is a far-reaching and ambitious reform strategy to bring about dramatic changes 
in the way that teaching and learning occurs in schools. Making the challenge even more formidable is the fact that America's Choice is generally adopted in low-performing schools with serious challenges in terms of organizational capacity, leadership, student and teacher mobility, etc. America's Choice combines both a broad philosophy of standardsbased schooling and more specific strategies for teaching and learning in the different content areas. To bring about these central changes, America's Choice has opted to rely heavily on full-time coaches at each America's Choice school. The job of the coach is to introduce teachers to the concept of standardsbased reform in general, to work initially on changing literacy instruction in particular, and to work in concert with the school's principal to modify the supporting organizational structure in order to facilitate the reforms. Coaches are the linchpins of the America's Choice reform strategy.

In this report, we have examined the multiple aspects of the coach's role in the implementation of America's Choice, including in-class and individual support for teachers and group-focused professional development activities. To produce this report, we visited 27 schools (18 elementary schools and 9 middle schools), interviewed principals, coaches, and teachers, and observed classroom instruction. We also attended NCEE training for coaches, interviewed relevant NCEE staff, and reviewed NCEE training materials. Overall, we interviewed 130 people and observed 71 classes of coaches and teachers. Our school visits occurred between March and May of 2002. This report is limited to an examination of coaching in Cohort 4 of America's Choice. We chose this cohort because it represented the latest refinement of the coaches' role at the time of the design of the study. One implication of this study design is that our report is limited to coaching in the first year of implementation of the design.
Based on our research, there can be no question that the America's Choice design, spearheaded by the coach, has influenced the way that teachers and administrators in the majority of schools we visited think about teaching and learning. There is evidence that the America's Choice philosophy of standards-based reform has begun to percolate through the participating schools and that instruction in most schools looks different than it did prior to the implementation of America's Choice. While we did not examine the impact of these efforts on student learning as part of this study, other CPRE studies have looked at the impact of America's Choice on student performance and found evidence of improved student learning in places where the design is implemented.

Yet, the burden placed on the coach to deeply implement America's Choice is onerous. Given the demands placed on the coaches, the ongoing challenges that face the schools within which they labor, and the preparation provided for coaches, one has to wonder about the ability of all but the most skilled and dedicated individuals to play this role effectively. It takes a special person to carry out the America's Choice design consistent with NCEE's vision. In the words of one principal:

Coaching provides ongoing consistent
support for the implementation and
instructional components [of the
America's Choice design]. It is non-
threatening and supportive - not
evaluative. It gives a sense of how good
professional development is. It also affords
the opportunity to see it work with
students. But, it hinges on the skills of the
coach, and that is a weakness.

In order to carry out their work, America's Choice coaches must make three major conceptual shifts - transformations, if you will - in their own views about education and instruction before they can even begin to think about teach- 
ing others about these three domains. First, they must understand and convey the concept of standards. Using a sophisticated set of performance standards as a living, breathing, three-dimensional document - one to wrestle with and to be provoked by - is a very different, and sometimes subtle, way of re-thinking about how to educate students. Second, they must master and communicate the structures of, and the concepts underlying, writers and readers workshops, which are very different way of teaching literacy involving a variety of sophisticated assessment techniques and purposeful instructional strategies. Third, they must understand and engage others in the formation of a professional learning community in order to commit others to their ongoing growth as learners as well as teachers.

America's Choice has made two strategic design changes with Cohort 4 that are clearly helping. First was the decision at the elementary level to eliminate the position of design coach in favor of having two literacy coaches. The presence of two literacy coaches at the elementary level means that coaches have more time to spend in the classroom with teachers, and that they can potentially draw upon the support and counsel of a colleague who has had the same training and is trying to do the same job. The fact that most elementary schools got further than middle schools in rolling out the America's Choice workshops is likely in part attributable to the fact that middle schools have a single literacy coach. While there may be some drawbacks to having eliminated the design coach position at the elementary level, they were not picked up by this study.

Second, the design has increased the role of the principal in carrying more formal authority for the implementation of the design. While this is a much needed redistribution of responsibility, we saw in our research that many coaches still did not feel sufficiently supported by or in sync with their principal. We suggest that it may be helpful to have coaches and principals participate in some training together. While this is critical early on, it should be sustained throughout the year in a subset of training. Principals and coaches particularly need to be in sync with each other about the development of professional learning communities in their schools.

A third design change for Cohort 4 schools served to increase pressure on coaches. This was the decision to increase the pace of implementation by expecting schools to roll out both writers and readers workshops in the first year. While it is good to be ambitious about the expectations for implementation, realistically only a few teachers were getting to readers workshop by the end of the first year, and overly ambitious expectations contributed to the coaches' sense of being overwhelmed.

Despite refinements to the America's Choice design, we nonetheless observed a wide variation in Cohort 4 schools across a number of areas. These included: progress made in their rollout of the design, the fidelity to literacy workshop structures of the observed instruction of both coaches and teachers, the quality and influence of group-focused professional development, and the problems that coaches encountered. Some of this variation, no doubt, can be traced back to the fact that schools come to the design from different places, with different capacities, and with different levels of commitment to standards-based reform (or any substantive change, for that matter). Other variation in school progress is attributable to the effort and quality of work done by the coach. Some of this variability can be reduced by better recruitment and preparation of coaches and better specification of their roles. As NCEE considers how to further improve the America's Choice design, we 
encourage further attention to influencing the selection, preparation, support, and monitoring of coaches.

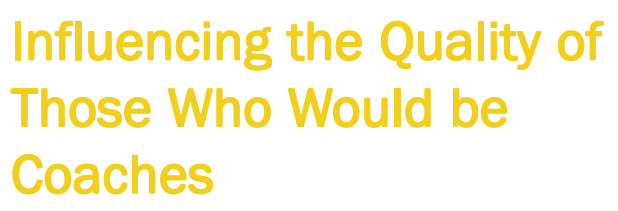

One of the ironies of NCEE's role as an external provider of educational assistance is that their influence is weakest at the crucial early junctures when decisions are made that have a great effect on the probability that the model will be successful in a particular school. One such decision is the choice of the coach. NCEE has learned in past experiences that they often cannot influence the selection of the coach, which is made in a principal's or district administrator's office often before America's Choice starts working with the school. But there are several ways that NCEE can influence this important decision. One would be to provide a much more robust description of the responsibilities of the coach in order to guide those doing the hiring and influence and inform prospective applicants. Another might be to provide school and district leaders with descriptions or vignettes of successful coaches to give a better sense of what the life of a coach is likely to be like. Both of these would possibly influence the people chosen to be coaches. Our data suggest that certain characteristics and factors influence the effectiveness of coaches. These include: strong human relations and communication skills, including, if possible, demonstrated success in training adults in situations where authority is collegial, rather than managerial; excellent teaching skills; a background in or at least strong interest in standards-based reform; the ability to be flexible and innovative in adapting the design to local circumstances (such as a lot of "scaffolding" done by two coaches to make the literacy workshops work for English Language Learners) and overcoming foreseeable problems, including teacher resistance; respect of the faculty; and strong, informed, and ongoing support and involvement of the principal. Writing a clear job description of what makes an effective coach and making it clear how important is this decision to the ultimate success of the reform, might help to guide decision makers in this crucial task.

\section{Better Preparing Coaches to do the Work of Standards- based Reform}

There are many things that a school needs to do when it embarks on standards-based reform with America's Choice. Capitalizing on this early period is hampered by the fact that coaches were generally not well versed in standards upon taking on their new role. One of the striking things we observed in our observations and interviews was how faint the presence of standards was in Cohort 4 schools. This is perhaps not surprising given that schools were in their first year of implementation and that two-thirds of the coaches reported to us that their exposure to standards-based reform was limited upon taking the job of coach. It is no wonder that coaches felt they were barely one step ahead of the teachers because they were. Given the constraints of lead time and the pressures to implement America's Choice from the get-go, what can America's Choice do to improve the knowledge of coaches in the critical early period of implementation? How can NCEE get coaches two steps ahead of the faculty of their school? There are several ways to think about this problem. One suggestion is to provide coaches with a crash course on standards in the summer before their school begins participating in America's Choice, although there may be cases where coaches are not in place at this juncture. Another option is to provide the crash course in the summer between the first and second years of the design. It is clear, however, that given the 
centrality of the coach's role in promoting the development of standards-based instruction in America's Choice schools, coaches themselves need a better command of standards.

If a solid understanding of standards is the "what," or content of the coach's job, we also detected some gaps in coaches' training as to the "how" of working with teachers to implement standards-based instruction - in other words, how best to be an effective coach. Although NCEE provides coaches with model lessons and detailed implementation plans and workshop guides, the training materials do not necessarily give specifics regarding how best to work with teachers. Quite a few coaches were at a loss regarding how to give feedback, or how to work with resistant teachers. This issue also arose during the coach literacy workshop training we attended. In designing future coach training sessions, NCEE could consider devoting a session to the issue of team building and overcoming resistance. Additional possibilities would be to put together an online collection of problem-solving strategies gleaned from the coaches themselves, and/or facilitate an online support network for America's Choice coaches working in different parts of the nation.

\section{Threading the Major Tasks of the Coach}

The underlying premise of the three major tasks of a coach - modeling instruction, leading teacher meetings, and facilitating study groups - is that these three experiences will provide mutually reinforcing experiences for teachers. The combination of direct practice (teaching writers and readers workshops), strategy acquisition (teacher meetings), and reflection (study groups) are together a promising strategy to build teachers' capacity to learn how to apply highquality standards-based instruction.
In our visits to Cohort 4 schools, we found that most teachers, coaches, and principals saw a connection between group-focused professional development activities and in-class technical coaching. Nonetheless, we also found that few respondents could distinguish between teacher meetings and study groups and their intended purposes (most claimed that there were no study groups at their schools), almost no schools were using the very detailed guides for coach facilitation of meetings and study groups, and that group professional development was often perceived as not being as helpful to understanding the literacy workshops as the instructional modeling. Implementation schedules of teacher meetings and study groups were often out of sync with the actual rollout of writers and readers workshops. Thus, teachers were often not studying in teacher meetings the activities they were trying to implement in their classes. Although most teachers reported that at least one teacher meeting had included a discussion of student work, regular, ongoing discussion of student work in relation to standards was clearly not yet occurring in the majority of Cohort 4 schools.

What should NCEE take from this? Should they try to tighten the connections between these three capacity-building strategies? Should they loosen the schedules so that coaches have more flexibility to match activities and practice? Should they make materials more generic so that overlaps from experiences are more likely to occur? Given the large variation in the speed of design rollout that we observed - which is a function of a number of factors, including school size, school capacity, and external events - it does not seem likely that tightening the sequences and overlap of the three experiences would resolve this problem. A far more promising solution would seem to be to allow the coach to modulate the introduction of activities for grade-level groups within the school, depending on 
their depth of implementation at a given time. Of course, this just increases reliance on the coach to understand the larger picture of the design enough to make smart decisions about the introduction of new materials. This leads to our final point - how to provide more support for coaches.

\section{Better Support for the Work of Coaches}

The other aspect of the design that NCEE might want to think about is the mechanism for supporting and monitoring coaches' implementation of the design. This report suggests that there is no question that the quality and pace of school implementation varied. But there are no easy answers as to how to reduce that variation. Several mechanisms do exist that could be used to support and monitor quality. First, NCEE could develop a robust observation tool that cluster leaders can use to assess the quality of the classroom instruction of coaches in the model classroom (and which coaches can use in the classrooms of teachers as well). The development of such an observation tool would not only help cluster leaders monitor quality, but would provide important support for coaches in that it would articulate in greater detail the distinctions between different levels of implementation depth. Further, if we assume that a coach's ability to facilitate implementation is greatly influenced by their own ability to implement the design, then an assessment of the quality of their implementation would give important insight into the progress of the work at a school.

Second, NCEE could revisit the distribution of cluster leader support for schools to confirm that the time that cluster leaders commit to each school is used most effectively. The ways that cluster leaders supported schools was not a major focus of this study, and, as men- tioned earlier in this report, most coaches believed the level of support provided was adequate. Taken as a whole, however, our interviews with, and observations of, coaches suggest a great deal of lingering uncertainty about what they should be doing despite the NCEE training - a problem that more proactive supervision could help to solve. We suggest that it could be helpful to have cluster leaders actually modeling instruction in their schools in addition to visiting classrooms in focused walks. We also suggest that some of the coach training occur in schools during school days so that coaches can receive experiences similar to those they are intended to deliver. We recognize that, at present cost levels, there are constraints as to the time that cluster leaders can allocate to each school, and we are suggesting that NCEE consider a redistribution of support, rather than providing additional support.

Third, NCEE could consider offering to train one or a few district-level administrators on the design with the purpose of having them support the America's Choice schools. The marginal cost of adding a few people to training sessions in each region would be minimal and the benefits could be substantive. This would serve several purposes. First, it would expand knowledge of America's Choice in the district, sowing the seeds for district support once the America's Choice contract is over. Second, as principals and coaches within districts often complain about lack of district understanding and support, it would provide an advocate for the design within the district. Third, over time, it would provide advocacy for district resources. 


\section{References}

Edwards, J. L., \& Newton, R. R. (1995, April). The effects of cognitive coaching on teacher efficacy and empowerment. Paper presented at the annual meeting of the American Educational Research Association, San Francisco, CA.

Gamston, R., Linder, C., \& Whitaker, J. (1993). Reflections on cognitive coaching. Educational Leadership, 51(2), 5761.

Gutierrez, K., Crosland, K., \& Berlin, D. (2001, April). Reconsidering coaching: Assisting teachers' literacy practices in the zone of proximal development. Paper presented at the annual meeting of the American Educational Research Association, Seattle, WA.

Kohler, F., \& Crilley, K. (1997). Effects of peer coaching on teacher and student outcomes. Journal of Educational Research, 90(4), 240-251.

National Center on Education and the Economy. (2001). Elementary Literacy Institute training materials. Washington, DC: Author.

Showers, B., \& Joyce, B. (1982). The coaching of teaching. Educational Leadership, 40(1), 4-10

Showers, B., \& Joyce, B. (1996). The evolution of peer coaching. Educational Leadership, 53(6), 12-16.

Supovitz, J. A. (2001). Translating teaching practice into improved student achievement. In S. H. Fuhrman (Ed.), From the capitol to the classroom: Standardsbased reform in the states (pp. 81-98).

Chicago: University of Chicago Press.

Veenman, S., Denessen, E., Gerrits, J., \& Kenter, J. (2001). Evaluation of a coaching program for cooperating teachers. Educational Studies, 27(3), 317-340. 